ACCEPTED MANUSCRIPT

\title{
Incoherent Thomson scattering measurements of electron properties in a conventional and magnetically-shielded Hall thruster
}

To cite this article before publication: Benjamin Vincent et al 2020 Plasma Sources Sci. Technol. in press https://doi.org/10.1088/1361$\underline{6595 / a b 6 c 42}$

\author{
Manuscript version: Accepted Manuscript \\ Accepted Manuscript is "the version of the article accepted for publication including all changes made as a result of the peer review process, \\ and which may also include the addition to the article by IOP Publishing of a header, an article ID, a cover sheet and/or an 'Accepted \\ Manuscript' watermark, but excluding any other editing, typesetting or other changes made by IOP Publishing and/or its licensors"
}

This Accepted Manuscript is @ 2019 IOP Publishing Ltd.

During the embargo period (the 12 month period from the publication of the Version of Record of this article), the Accepted Manuscript is fully protected by copyright and cannot be reused or reposted elsewhere.

As the Version of Record of this article is going to be / has been published on a subscription basis, this Accepted Manuscript is available for reuse under a CC BY-NC-ND 3.0 licence after the 12 month embargo period.

After the embargo period, everyone is permitted to use copy and redistribute this article for non-commercial purposes only, provided that they adhere to all the terms of the licence https://creativecommons.org/licences/by-nc-nd/3.0

Although reasonable endeavours have been taken to obtain all necessary permissions from third parties to include their copyrighted content within this article, their full citation and copyright line may not be present in this Accepted Manuscript version. Before using any content from this article, please refer to the Version of Record on IOPscience once published for full citation and copyright details, as permissions will likely be required. All third party content is fully copyright protected, unless specifically stated otherwise in the figure caption in the Version of Record.

View the article online for updates and enhancements. 


\title{
Incoherent Thomson scattering measurements of electron properties in a conventional and magnetically-shielded Hall thruster
}

\section{Benjamin Vincent, Sedina Tsikata and Stéphane Mazouffre}

ICARE, CNRS, 1C avenue de la Recherche Scientifique, 45100 Orléans, France

E-mail: benjamin.vincent@cnrs-orleans.fr

29 December 2019

\begin{abstract}
.
Reliable measurements of electron properties are key for the validation of simulations of Hall thrusters and similar plasma sources. In this paper, a recently-developed incoherent Thomson scattering diagnostic is successfully applied to electron property measurement in a low-power Hall thruster discharge. Investigations of electron properties along radial and azimuthal directions in both conventional and magnetically-shielded architectures are performed. The high diagnostic sensitivity gives access to electron property measurements in a plasma environment with densities as low as $10^{16} \mathrm{~m}^{-3}$. Electron temperatures reaching several tens of $\mathrm{eV}$ and drift velocities on the order of $10^{6} \mathrm{~m} \mathrm{~s}^{-1}$ are measured in the exit plane region. The impact of the magnetic field (intensity and direction) and discharge voltage are investigated.
\end{abstract}




\section{Introduction}

A Hall thruster is an electric propulsion device first conceived and developed in the mid-1960s in the Soviet Union. This thruster was operated for the first time in space aboard the USSR Meteor satellite in 1972 [1-4] and is today widely used for station-keeping on telecommunications satellites [5-7]. Interest in such technologies is driven by the significant fuel mass economies achievable in comparison to chemical propulsion-based systems. In spite of the long flight heritage of these devices, an understanding of their underlying physics remains poor: questions such as the nature of instabilities occurring over different temporal and spatial scales [8], interactions between the thruster plasma and external cathode plasma [9], the origins of non-Maxwellian electron velocity distribution functions $[10,11]$, the nature of plasmawall interaction and the consequences of secondary electron emission [12-15], all remain to be fully understood. Early simulation efforts have shed light on aspects such as Hall thruster instabilities and particle dynamics, illustrated for example in Refs. 16-19 and newer modeling efforts have been undertaken in several research teams in recent years, including in the teams of Refs. 4, 20-24, in order to advance physical understanding and ultimately, make possible fullypredictive discharge modeling. However, all codes must be fully validated through comparison with accurate experimental measurements for electron properties.

Electron property measurement in Hall thrusters has so far been extensively performed with Langmuir probes, including in Refs. 25-28, to name only a few. Optical emission spectroscopy has also been used as an alternative method to estimate electron temperature in thrusters in works including Refs. 29-32. Such techniques are adequate for far plume measurements, however, their application in the acceleration region of the Hall thruster plasma has limitations [33]. The expected high electron densities and temperatures and the presence of strong magnetic fields in this region complicate signal measurement and interpretation. More specifically, for Langmuir probes, the measurement duration must be minimized with fast translation stages in order to avoid sputtering, and the helical trajectories of magnetized electrons require more complex probe theories to interpret the signals acquired. For optical emission spectroscopy, the use of line intensities in collisional-radiative models to determine electron temperatures is associated with inaccuracies for both low and high electron temperatures [30, 31].

Thomson scattering applied to such measurements offers the possibility of unambiguous and perturbationfree measurement of electron properties. The challenge associated with this technique is achieving a high enough diagnostic sensitivity for measurements in a low-density plasma, such as that of the Hall thruster. In the coherent regime, Thomson scattering has already proven to be an efficient technique to measure electron density fluctuations in such plasmas, seen in the implementation of the PRAXIS diagnostic [34]. In the incoherent regime, Thomson scattering allows measurement of thermal properties of electrons. This technique has already been successfully used in several low-pressure plasma sources to estimate electron density and temperature, including in Refs. 35-41 or even the electron drift velocity in Ref. 42.

Recent studies by Washeleski [43, 44] have shown that this technique can be used in Hall thrusters, but the low signal levels and large stray light intensities make its application challenging. In our previous work, a sufficiently sensitive diagnostic named THETIS (THomson scattering Experiments for low-Temperature Ion Sources) was developed and successfully tested on a cathode discharge [45] and a planar magnetron [46]. In this paper, the results from the implementation of this diagnostic on a low-power Hall thruster are presented.

In Section 2, a description of the main features of the diagnostic and the data analysis procedures used are presented. Results of experimental investigations on two thruster architectures under different discharge conditions are discussed in Section 3. A summary of the main results is given in Section 4.

\section{Experimental schemes}

\subsection{Overview of the experimental set-up}

\subsubsection{Test facility}

Experiments were performed in the NExET (New Experiments in Electric Thrusters) vacuum chamber at ICARE. This chamber is a stainless steel cylinder $0.7 \mathrm{~m}$ in diameter and $1.7 \mathrm{~m}$ in length, equipped with a primary dry pump, turbomolecular pump, and cryogenic pump. The pressure was measured with a Leybold Penningvac PTR 90 gauge positioned at the top of the chamber, approximately $1 \mathrm{~m}$ downstream of the gas injection position. The pumping assembly achieves a base pressure of $10^{-4} \mathrm{~Pa}$ and operating pressure below $2 \times 10^{-2} \mathrm{~Pa}$ with a xenon mass flow rate up to $2.5 \mathrm{mg} \mathrm{s}^{-1}$. Background pressure effects are not negligible [47] for these operating conditions. Ionization of the ambient gas is expected to contribute to higher discharge currents than at lower chamber pressures, for the same applied voltage. Slightly higher electron densities (due to ambient ionization) and lower electron temperatures (due to increased electron-neutral collisions) are also expected under our operating conditions. Such effects have been observed for previous studies investigating facility effects, for example, in Ref. 48. 
The discharge voltage is regulated with an SM1500 Delta Elektronika DC power supply. Discharge current is measured through a $0.5-1.0 \mathrm{~W}$ Stangenes current transformer probe and monitored with a LeCroy HDO6104 digital oscilloscope.

\subsubsection{Plasma sources}

Incoherent Thomson Scattering (ITS) measurements were performed on two $200 \mathrm{~W}$ Hall thrusters of the ISCT200 (ICARE Small Customizable Thruster $200 \mathrm{~W}$ ) type: the ISCT200-GEO and ISCT200-MS. Both thrusters were equipped with $\mathrm{BNSiO}_{2}$ channels and have the same channel width and mean diameter, a geometry referred as " $2 \mathrm{~S}_{0}$ " in previous publications [49]. The so-called $2 \mathrm{~S}_{0}$ geometry corresponds to a configuration with a channel width to diameter ratio twice as large as the usual value. In this paper, thrusters were operated with xenon injected through a porous ceramic gas distributor placed behind a stainless steel ring anode, as seen in Fig. 2.

The ISCT200-GEO has been extensively studied at the ICARE laboratory [50]. It has a standard magnetic field topology, achieved using an assembly of permanent magnets, with the maximum field intensity at the center of the channel and inside the exit plane. The magnetic field intensity is changed by varying the number of magnets of the internal and external magnetic circuits. Three peak magnetic fields were used in this study: $\mathrm{B}_{\text {low }}(15 \mathrm{mT}), \mathrm{B}_{\text {mid }}(25 \mathrm{mT})$ and $\mathrm{B}_{\text {high }}(31.5 \mathrm{mT})$. The ISCT200-GEO is shown in Figure 1a. The typical magnetic profile of this thruster is illustrated in the upper half of Figure 2.

The ISCT200-MS has been studied in recent years $[51,52]$ and has a magnetic circuit designed for "magnetic shielding", a concept originally developed by researchers at NASA-JPL [53] and recently extended to miniature Hall thrusters (in the $300-500 \mathrm{~W}$ range) by Conversano and colleagues [54]. This configuration is designed to reduce channel erosion [55] and the maximum magnetic field position is slightly shifted downstream of the exit plane. In this work, measurements with a peak magnetic field of $15 \mathrm{mT}$ $\left(\mathrm{B}_{\text {low }}\right)$ are discussed. The ISCT200-MS is shown in Figure $1 \mathrm{~b}$ and the typical magnetic field line shape of this shielded thruster is illustrated in the lower half of Figure 2.

Both thrusters were operated with a 5 A MIREAtype hollow cathode equipped with a $\mathrm{LaB}_{6}$ emissive element heated with $130 \mathrm{~W}$ of power and run with a xenon flow rate of $0.2 \mathrm{mg} \mathrm{s}^{-1}$.

The laser beam used to probe the plasma was kept fixed. The thrusters were translated along the x-axis (Figure 3) for axial exploration of electron properties. Displacements along the y-axis and z-axis were used to change the scattering configuration.

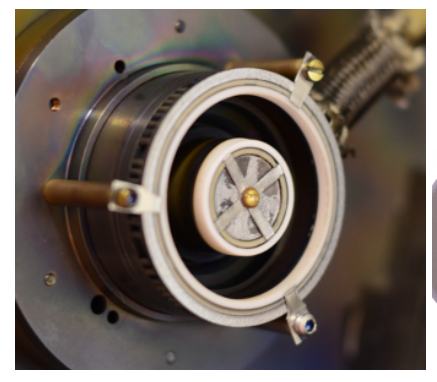

(a) The ISCT200-GEO Hall thruster (unshielded, standard)

Figure 1: Hall thruster models used for ITS investigations

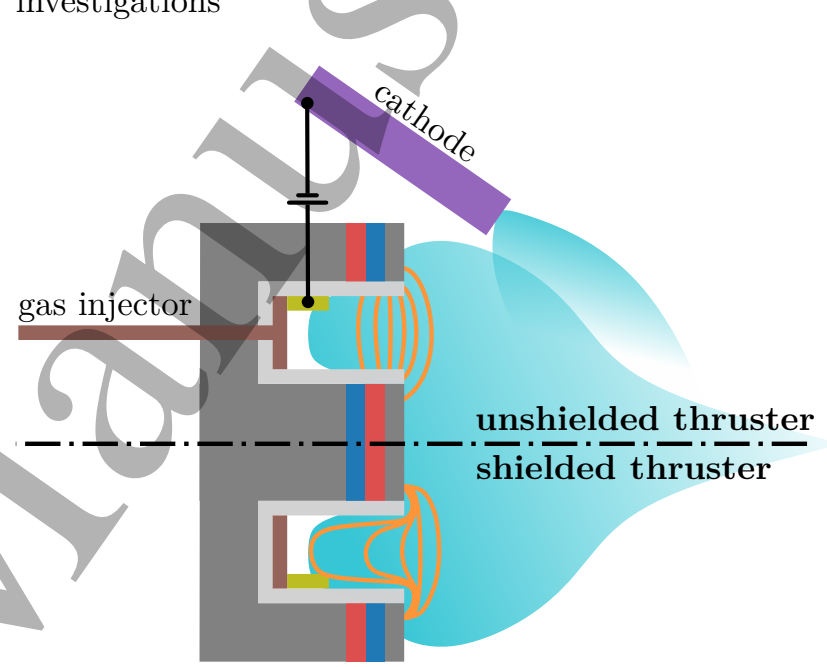

ceramic walls (BN-SiO2)

magnetic circuit

magnets

anode

plasma

magnetic field lines

Figure 2: Hall thruster geometry. Typical magnetic field line shapes for unshielded (top half) and shielded (bottom half) Hall thrusters are compared.

\subsubsection{Description of the ITS diagnostic}

A detailed description of the recently-developed ITS diagnostic named THETIS and the procedure for data analysis can be found in a published article [45]. Only a brief description is made here.

\section{Optical elements}

A schematic of the THETIS diagnostic transmission and detection branches is shown in Figure 3.

The transmission branch produces the scattering signal. This is drawn with a dark green line in Figure 3. It starts with a frequency-doubled, $10 \mathrm{~Hz}$ pulsed Q- 
switch Nd:YAG laser delivering pulses of $430 \mathrm{~mJ}$ (pulse width $6 \mathrm{~ns}$ ). Mirrors and lenses conduct and focus the laser beam into the observation volume of the detection branch. The laser beam is finally sent to a largeaperture beam dump to reduce back reflections.

The detection branch is used to analyze the Thomson scattering signal and is indicated with a light green line in Figure 3. It starts at the observation volume position, where the light from the transmission branch has been focused. From this volume, the Thomson scattering radiation and other stray radiation is emitted. This signal is focused with a collection lens onto the entrance of an optical fiber bundle, composed of a $5 \times 3$ array of $300 \mu \mathrm{m}$-diameter fibers. In the configuration of these experiments, the collection lens referred as $L 1$ is a $100 \mathrm{~mm}$-diameter plano-convex lens with a $200 \mathrm{~mm}$ focal length positioned at the top of the vacuum chamber $0.564 \mathrm{~m}$ from the observation volume (magnification factor of 0.55 ). The fiber bundle transmits the collected light to the optical table, where light from a $1 \times 15$ array of the fiber stack is collimated with a $50 \mathrm{~mm}$-diameter plano-convex lens of $125 \mathrm{~mm}$ focal length. The stray light from reflections and Rayleigh scattering are then attenuated with a $25 \mathrm{~mm} \times 25 \mathrm{~mm}$ VBG-NF (Volume Bragg Grating Notch Filter). The remaining light is focused onto the $1 \mathrm{~mm}$-wide entrance slit of a spectrometer using a $300 \mathrm{~mm}$ focal length lens to fit the $\mathrm{f} / 9.7$ numerical aperture of the spectrometer. Light is then typically dispersed by the spectrometer with a 600 lines $\mathrm{mm}^{-1}$ grating suited for measurement of the high electron temperatures (tens of $\mathrm{eV}$ ) expected at the Hall thruster exit plane. Finally, the dispersed light is detected with an ICCD camera with a 10 ns gate, synchronized with the Q-switch signal from the laser.

\section{Scattering configuration}

With this detection branch configuration, the observation volume is $0.3 \mathrm{~mm}$ in diameter and $2.7 \mathrm{~mm}$ in length. Plasma properties measured with the diagnostic correspond to an average over this volume.

Electron properties along an observation wave vector $\vec{k}$ are probed with Thomson scattering diagnostics. As represented in Figure 4, the observation wave vector direction in this work is defined by the vector equation $\vec{k}=\overrightarrow{k_{i}}-\overrightarrow{k_{s}} \cdot \overrightarrow{k_{i}}$ corresponds to the wave vector of the incident laser beam and $\overrightarrow{k_{s}}$ corresponds to the wave vector of the light entering the detection branch.

In these experiments, the thruster vertical position was chosen so that the laser beam passes at a height $r_{\text {mean }} \times \cos \left(45^{\circ}\right)$ above the midplane (where $r_{\text {mean }}$ is the mean channel diameter). With this configuration, a lateral translation of the thruster allows the alignment of the observation wave vector along either the radial or azimuthal direction, if the observation volume is positioned in front of the channel mean diameter.

By convention, a positive spectral shift of the Thomson spectrum corresponds to a positive electron drift velocity. With the data analysis convention used, a positive drift velocity measured along the azimuthal direction corresponds to electrons drifting in the anticlockwise direction (i.e. along $\vec{k}$ ). Along the radial direction, a positive drift will correspond to an electron moving towards the internal pole of the thruster.

\section{Data analysis}

For calibration of the transmission factor of the detection branch, the same procedure as that discussed in Ref. 45 is followed. The vacuum chamber was filled with nitrogen to a pressure of $1000 \mathrm{~Pa}$ and the signal from Raman scattering accumulated over 6000 laser pulses. Due to the high electron temperatures expected with the Hall thruster, the Raman calibration, as well as most of Thomson spectrum acquisitions, were performed with the 600 lines $\mathrm{mm}^{-1}$ grating and a central wavelength of $532 \mathrm{~nm}$. The spectrometer slit width was set to $1 \mathrm{~mm}$. With this grating and slit width the Boltzmann distribution of the vibrational states, and not the individual Raman lines, is resolved.

In our recent work, the Thomson scattering signal analyzed is obtained from the subtraction of two consecutive spectra types accumulated over 6000 laser pulses. The first record ("Thomson"), is obtained with the plasma and laser on. During this record, the Thomson scattering, plasma emission, electronic noise and the remaining stray light from Rayleigh and reflections are measured. The second record, ("background"), is obtained with the plasma on but the laser off. During this record, only the plasma emission and electronic noise signals are measured. For both plasma sources studied to date (the hollow cathode and planar magnetron) the subtraction of these two records were enough to isolate Thomson scattering from plasma emission lines.

For analysis of the Thomson spectra in the present work, the data analysis procedure has been modified with respect to the procedure described in Ref. 45 to be more robust to potential distortion from plasma emission lines. Due to the high electron temperatures, the spectral range covered by the Thomson scattering signal is large. Inside the $28.6 \mathrm{~nm}$ spectral range observed, several intense emission lines from the Hall thruster plasma are present. Even during the $10 \mathrm{~ns}$ observation gate of the detector, some emission lines remain at amplitudes at least one order of magnitude above the maximum Thomson scattering signal. The subtraction of the plasma emission record can lead to dips in the final spectrum (for example, near $530 \mathrm{~nm}$ and $542 \mathrm{~nm}$ in the Thomson spectrum of Figure 5), or leave stray peaks (for example near $526 \mathrm{~nm}$ in the 


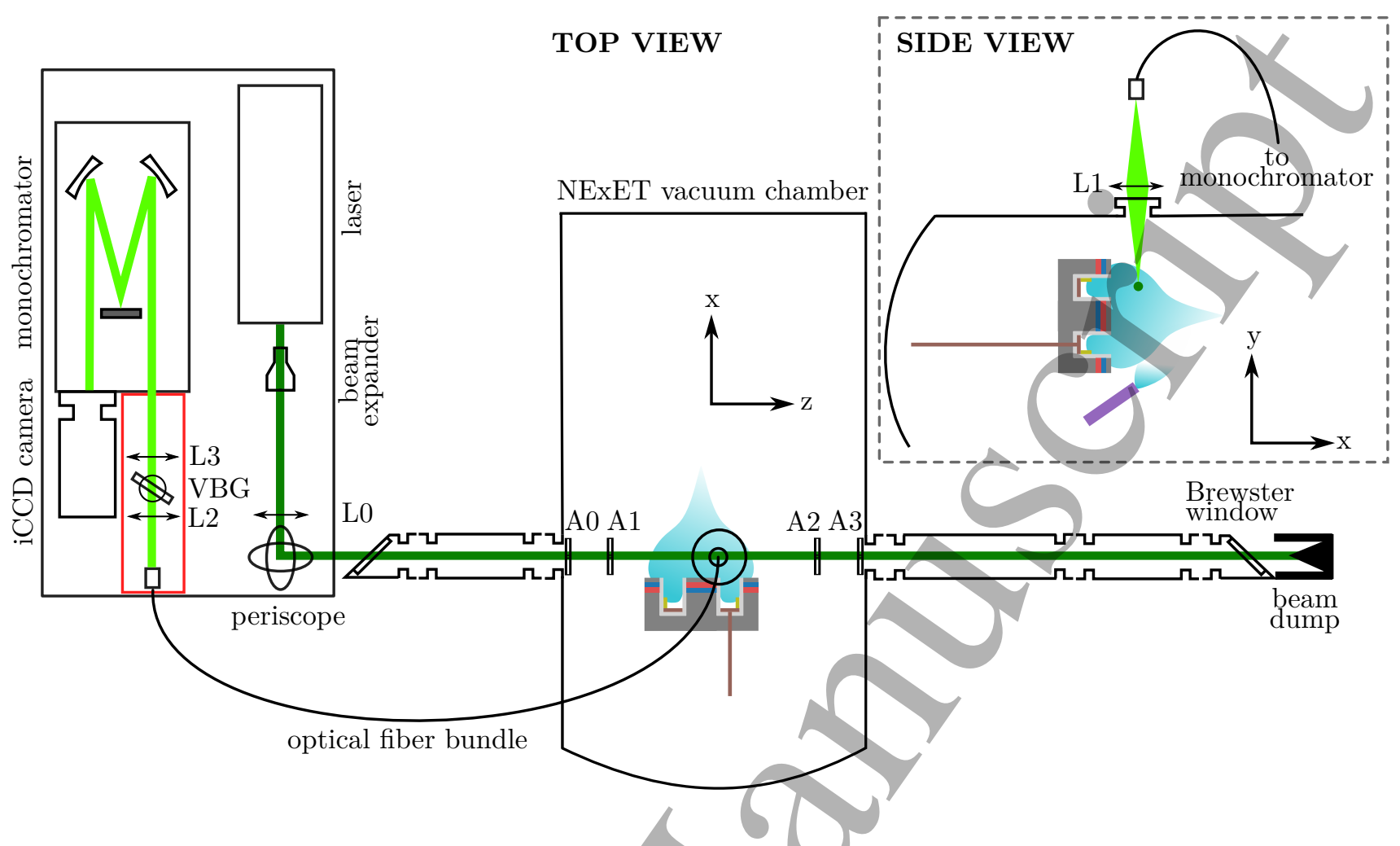

Figure 3: Schematic view of the THETIS diagnostic setup for Hall thruster investigations (not to scale). The transmission branch is indicated with a dark green line and the detection branch with a light green line. $L 0$, $L 1, L 2$ and $L 3$ indicate lenses; $A 0, A 1, A 2$, and $A 3$ indicate apertures; VBG indicates the notch filter. The plasma volume is shown in blue.

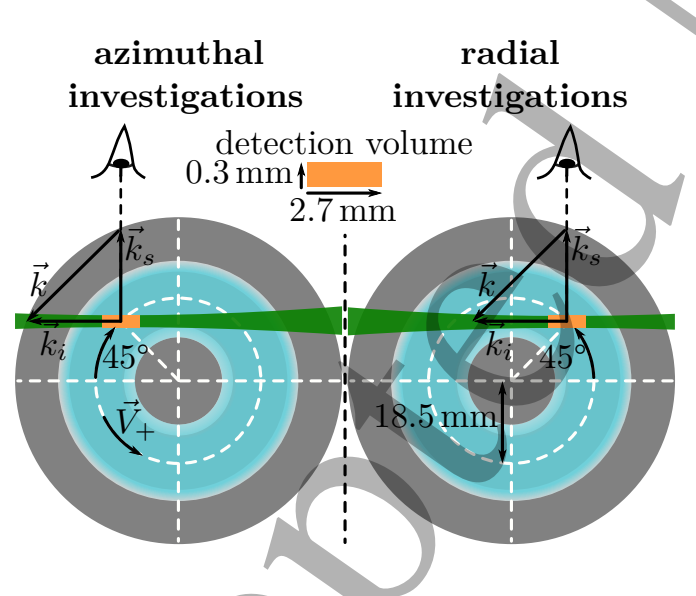

Figure 4: Scattering configurations (not to scale) used for investigation of electron properties along the azimuthal (left) and radial (right) directions. Both views are presented facing the thruster plume (in blue). The laser beam is in green and the detection volume in orange.

same figure). The presence of residual plasma emission contributions can be accounted for in two ways.

A slow drift in the plasma conditions due to thermalization of the thruster could lead to a drift of plasma emission intensity. This slight difference occurring between the "Thomson" and "background" records would appear significant in comparison to the weak Thomson scattering signal. Another possible reason is that during "Thomson" records, the emission lines are measured in the presence of the intense electric field of the laser. This electric field may induce significant Stark splitting and shifting [56, 57]. During the "background" records such splitting is absent, the recorded emission lines would not be identical to those obtained during "Thomson" records.

To limit distortion by the emission lines, the Thomson spectra are analyzed in the following way before fitting. Negative values of intensity (counts) below three times the standard deviation of the electronic noise level from the $\mathrm{iCCD}\left(\sigma_{\text {elec noise }}\right)$ can only be attributed to distortion from plasma emission lines following subtraction. Intensities of the acquired Thomson spectra below this critical value were truncated at this value $\left(3 \times \sigma_{\text {elec noise }}=-2.5\right.$ counts with the experimental parameters used during the campaign). To mitigate the positive distortion of the Thomson spectrum (i.e., cases where the residual emission lines add up positively to the Thomson 


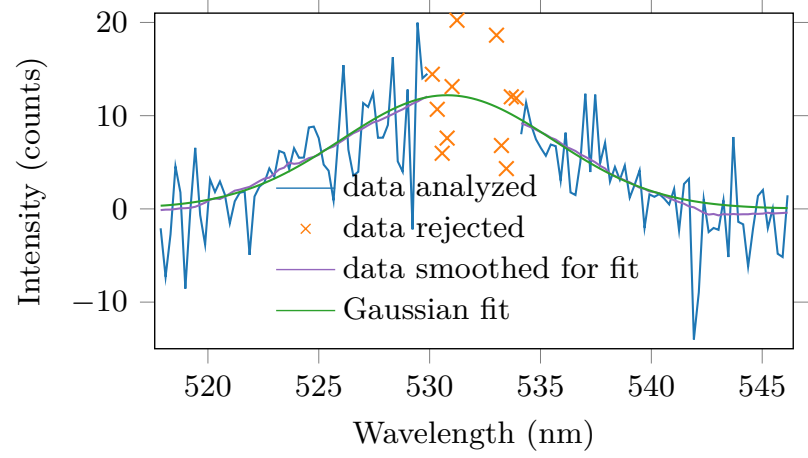

Figure 5: Thomson spectrum example obtained along the azimuthal direction with the ISCT200-GEO thruster. The corresponding electron density and temperature are $\left((2.6 \pm 0.2) \times 10^{16} \mathrm{~m}^{-3}\right.$ and $(20 \pm 2) \mathrm{eV}$ respectively. Discharge parameters are a xenon flow rate of $1.6 \mathrm{mg} \mathrm{s}^{-1}$, discharge voltage of $250 \mathrm{~V}$ and a discharge current of $1.13 \mathrm{~A}$. This spectrum is obtained for an axial distance from the exit plane of $4 \mathrm{~mm}$ and peak magnetic field of $25 \mathrm{mT}$ at the exit plane.

signal), a Savitzky-Golay filter was applied to the Thomson spectrum. This low-pass filter reduces the fast rises of intensity due to plasma emission lines, while leaving unchanged the slowly-varying Thomson spectral shape. This filter was applied independently on the left and right sides of the Thomson spectrum, separated by the rejected central spectral range around $532 \mathrm{~nm}$.

Data obtained from this preliminary data processing is used as input to the algorithm for Thomson spectral analysis presented in Ref. 45. A Gaussian function convoluted with the instrument function is used as a fitting function for the Thomson spectrum. From the Gaussian standard deviation, an electron temperature is determined, while the shift of the Gaussian mean from the laser wavelength is used to determine the bulk electron drift velocity. Finally, the integrated intensity of the Thomson spectrum gives an estimation of the electron density averaged inside the observation volume.

Similar to the procedure presented Ref. 45, uncertainties were estimated for each electron parameter. Uncertainties were systematically calculated from the quadratic mean of the propagation of the main sources of uncertainty. The principal sources of this uncertainty were the uncertainty in the value of the differential cross-section for Raman scattering of $\mathrm{N}_{2}(\approx 8 \%)$, the laser energy fluctuations $(<1 \%)$ and the quality of the fit to the data, determined from the co-variance matrix obtained during fitting, and dependent on the signal-to-noise ratio of the fitted data.

The spectrum example provided in Figure 6

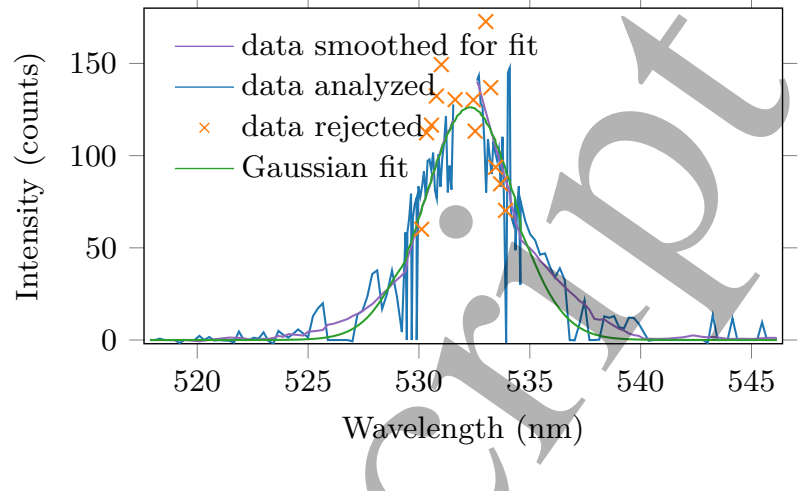

Figure 6: Thomson spectrum example obtained along the azimuthal direction with the ISCT200-MS thruster. The corresponding electron density, temperature and drift velocity are $(1.3 \pm 0.1) \times 10^{17} \mathrm{~m}^{-3},(3.7 \pm 0.3) \mathrm{eV}$ and $(93 \pm 12) \mathrm{kms}^{-1}$, respectively. Discharge parameters are a xenon flow rate of $2.3 \mathrm{mg} \mathrm{s}^{-1}$, discharge voltage of $112 \mathrm{~V}$ and a discharge current of $2.67 \mathrm{~A}$. This spectrum is obtained for an axial distance from the exit plane of $2 \mathrm{~mm}$ and a peak magnetic field of $15 \mathrm{mT}$ at the exit plane.

shows a case obtained for lower electron temperatures, for which both the 600 lines $\mathrm{mm}^{-1}$ grating and a less-dispersive 2400 lines $\mathrm{mm}^{-1}$ grating were used to constitute the spectra. Origins of the weakly nonGaussian spectrum shape will be discussed in a forthcoming paper.

\section{Results and discussion}

\subsection{Preliminary remarks}

To determine whether the electron properties are isotropic, measurements along both the radial and azimuthal directions were made by switching between the two scattering configurations presented in Section 2.1.3. In the subsequent plots, values of electron properties obtained along the azimuthal direction are plotted with blue triangles and radial observations plotted with yellow circles. While the observation of non-isotropic electron temperature or drift velocity has a physical significance, this is not the case for electron density, which is expected to be the same in both directions. Differences in the electron density measured at the azimuthal and radial positions may be due to azimuthal plasma non-uniformity (possibly influenced by the cathode position [58]), spatial inhomogeneities of the magnetic field or gas feeding [59]). Electron beam fluorescence [60] might be a way to verify the azimuthal uniformity of the neutral gas injection in the future. A slight displacement (below $0.3 \mathrm{~mm}$ ) of the measurement position as the thruster is translated laterally to 
switch between the two scattering configurations may also account for small differences in measured density between the azimuthal and radial positions.

As mentioned previously, for reliable Thomson spectrum measurement, an average over 6000 laser pulses was necessary to increase the signal-to-noise ratio. For the presented study, the Thomson scattering spectrum is measured at random phases in the discharge current oscillation and is therefore expected to be representative of the mean electron properties. Phase-resolved measurement of electron properties will be performed in forthcoming studies, and has indeed already been performed in another of our studies on pulsed plasmas [46].

Axial exploration of electron properties was performed within the axial range $2-40 \mathrm{~mm}$ in the azimuthal direction and $3-40 \mathrm{~mm}$ in the radial direction with respect to the exit plane. The closest approach to the exit plane for both directions is that for which stray light reflections can be sufficiently attenuated for the Thomson signal to be unobscured. The difference in the closest approach for the two directions is due to the different levels of light reflected off the central pole which enter the detection branch. While with the radial scattering configuration the inner pole behind the observation volume is directly illuminated, it is not the case with the azimuthal scattering configuration. The furthest axial distance is that for which the plasma density remains sufficient for a signal to be detected. As shown with the Thomson spectrum example in Figure 5, a Gaussian curve can be fitted to the data with confidence despite the low electron density.

\subsection{Influence of the magnetic field}

\subsubsection{Magnetic field intensity}

Axial profiles of electron properties with the ISCT200-GEO for various mâgnetic field intensities were determined. For each magnetic field, the discharge power was kept constant at $285 \mathrm{~W}$, with the discharge voltage and current of respectively $250 \mathrm{~V}$ and $1.14 \mathrm{~A}$. The discharge current was kept constant using an adjustment of the xenon mass flow rate to $1.18 \mathrm{mg} \mathrm{s}^{-1}, 1.60 \mathrm{mg} \mathrm{s}^{-1}$ and $1.38 \mathrm{mg} \mathrm{s}^{-1}$ for, respectively, the $\mathrm{B}_{\text {low }}, \mathrm{B}_{\text {mid }}$ and $\mathrm{B}_{\text {high }}$ magnetic field intensities. Results from these explorations are shown in Figure 7.

As shown in the first row of Figure 7, the electron density has only a weak dependence on the magnetic field intensity. The different values of electron density remains between $4.5 \times 10^{16} \mathrm{~m}^{-3}$ and $0.8 \times 10^{16} \mathrm{~m}^{-3}$ from $2 \mathrm{~mm}$ to $40 \mathrm{~mm}$ from the exit plane. The electron density is lowest with the $\mathrm{B}_{\text {low }}$ configuration (possibly attributable to less efficient confinement) and the highest electron density is observed with the nominal
$\mathrm{B}_{\text {mid }}$ magnetic field.

In Figure 7, the electron temperatures of the $\mathrm{B}_{\text {mid }}$ configuration decrease monotonically from approximately $40 \mathrm{eV}$ near the exit plane to $10 \mathrm{eV}$ at $40 \mathrm{~mm}$ downstream, for both azimuthal and radial directions. These values are on the same order of magnitude as recent PIC simulations predictions [61].

In the $\mathrm{B}_{\text {low }}$ configuration, the electron temperatures are higher than for the $\mathrm{B}_{m i d}$ case, and azimuthal temperatures exceed the radial temperatures. There are some possible reasons for such anistropy in temperature. A weaker magnetic trap, provided a similar electric field amplitude is achieved for the $\mathrm{B}_{\text {low }}$ and $\mathrm{B}_{\text {mid }}$ configurations, would lead to higher $E \times B$ drift velocities. We note that the $E \times B$ drift is the driver of azimuthal instabilities like the electron cyclotron drift instability [62], confirmed in thruster simulations to contribute to electron heating in both azimuthal and radial directions (with a stronger contribution in the azimuthal direction) $[14,63]$. Radial electron temperatures may also be lower due to radial losses of energetic electrons to the walls and the injection of cooler wallemitted electrons into the plasma. This latter effect might, however, be more significant inside the thruster channel. In order to fully understand the causes of the anisotropy, complementary measurements of (i) the electric field axial profiles using laser-induced fluorescence, and (ii) instabilities implicated in heating using coherent Thomson scattering would be necessary. Investigations of the influence of geometrical effects on anisotropy (varying channel widths at fixed mean channel diameters) could also be instructive.

The reproducibility of the electron properties presented in this paper has been confirmed by a few successive measurements performed under identical plasma conditions, which produce identical spectra in amplitude and width. Variations from one measurement to another are due generally to variations in the level of the emission lines.

The time-varying discharge current and the associated power spectrum density for the different magnetic fields are shown in Figure 8 and Figure 9. The integral of the power spectrum density over frequency between $10^{3} \mathrm{~Hz}$ and $2 \times 10^{7} \mathrm{~Hz}$ gives $9.8 \times 10^{-3} \mathrm{~A}^{2}$, $3.6 \times 10^{-3} \mathrm{~A}^{2}$ and $81 \times 10^{-3} \mathrm{~A}^{2}$ for respectively the $\mathrm{B}_{\text {low }}, \mathrm{B}_{\text {mid }}$ and $\mathrm{B}_{\text {high }}$ configurations. For these configurations, the electron density decreases as the power contained in discharge current oscillations increases. The larger discharge current oscillations observed in the $\mathrm{B}_{\text {low }}$ and $\mathrm{B}_{\text {high }}$ configurations may be linked to axial plasma oscillations (such as transit time oscillations [61]) which may contribute to a larger anisotropy in the electron temperatures and may be associated with poorer electron confinement. This study on the correlation between the power density spectrum of the 


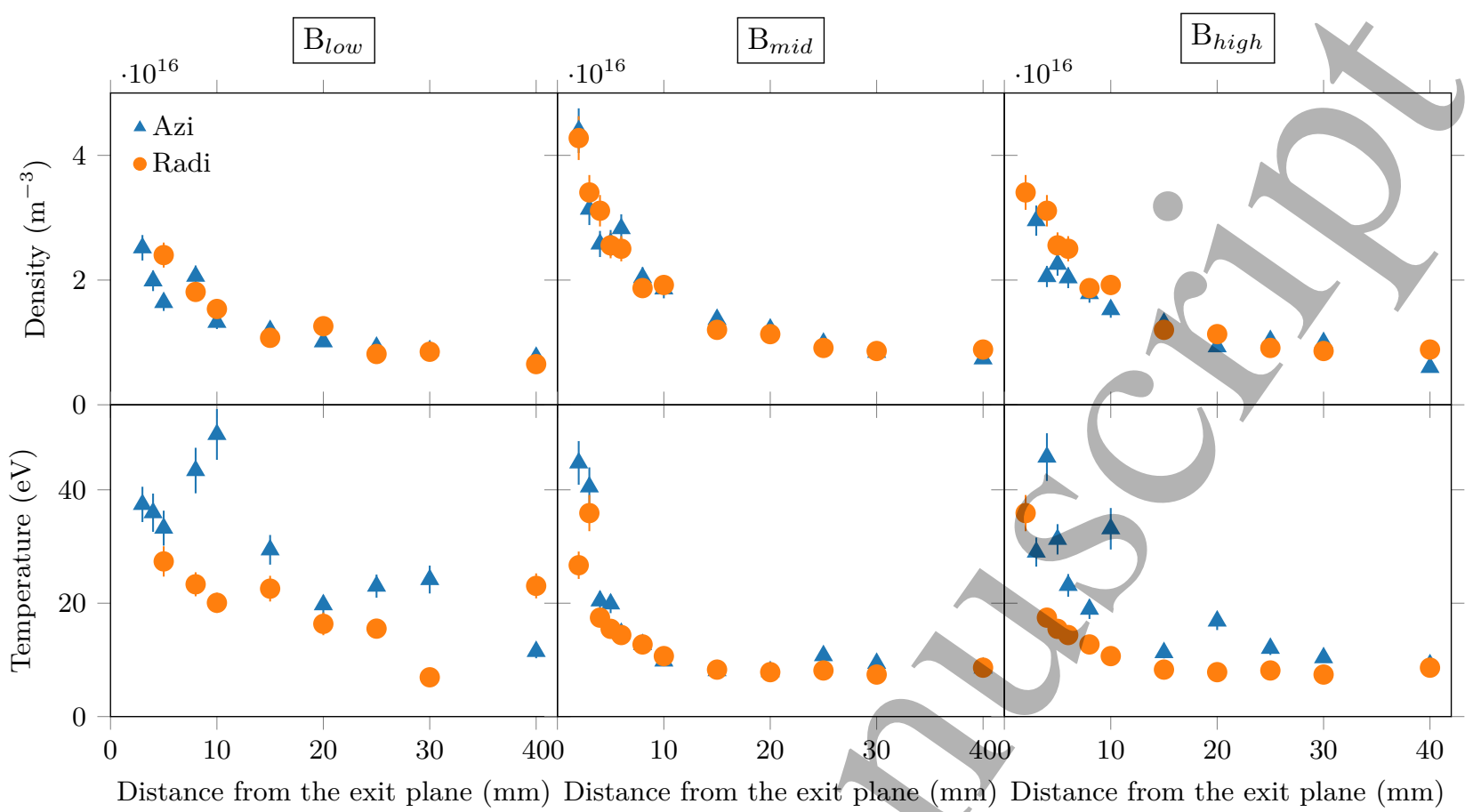

Figure 7: Comparison of electron density (first row) and electron temperature (second row) obtained with the ISCT200-GEO thruster at $250 \mathrm{~V}$ and $1.14 \mathrm{~A}$ for different magnetic field intensities. From left to right, the columns correspond to the $\mathrm{B}_{\text {low }}, \mathrm{B}_{\text {mid }}$ and $\mathrm{B}_{\text {high }}$ configurations.

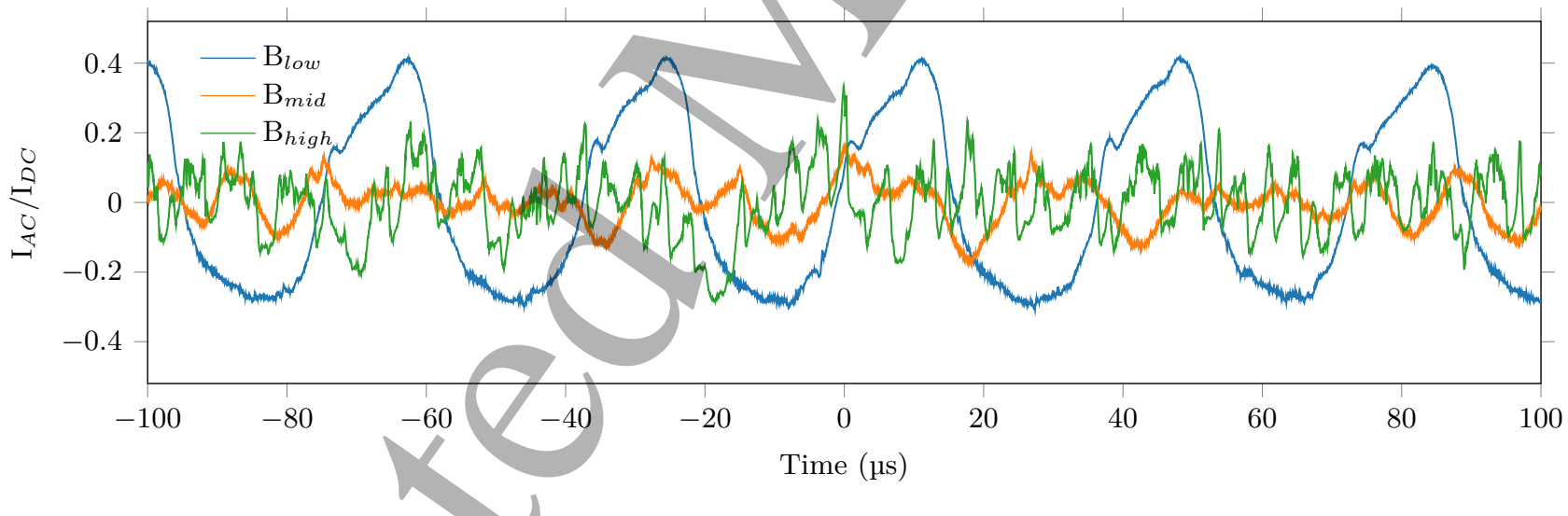

Figure 8: $\mathrm{AC}$ component of the discharge current for $\mathrm{B}_{l o w}, \mathrm{~B}_{\text {mid }}$ and $\mathrm{B}_{\text {high }}$ magnetic field intensities. The DC component of the current is $1.14 \mathrm{~A}$ and the discharge voltage $250 \mathrm{~V}$.

discharge current and the presence of anisotropic electron temperature values should be repeated in order to verify the statistical significance of this observation.

An order of magnitude estimate of the expected electron density can be determined using the expression for the xenon mass flow rate:

$\dot{m}_{n}=\frac{1}{\eta_{\text {prop }}} \dot{m_{i}}=\frac{1}{\eta_{\text {prop }}} n_{i} m_{i} A v_{i}$

where $\dot{m}_{n}$ and $\dot{m}_{i}$ are the mass flow rate of xenon atoms and ions, respectively, through a section $A$. $\eta_{\text {prop }}$ is the propellant utilization efficiency. $m_{i}$ and $v_{i}$ correspond to, respectively, the mass and velocity of xenon ions while $n_{i}$ is the density. Under the hypothesis of quasineutrality this equation can be used to estimate $n_{e}$ :

$n_{e}=\frac{\eta_{\text {prop }} \dot{m}_{n}}{m_{i} A v_{i}}$

At the position $10 \mathrm{~mm}$ downstream of the exit plane, we may assume that most of the ions have been accelerated. Using previously-estimated values of the parameters of Equation 2 with the same thruster at similar discharge conditions ( $\eta_{\text {prop }} \approx 80 \%$ [64], $v_{i} \approx 16 \mathrm{~km} \mathrm{~s}^{-1}[65]$ and a channel surface $A$ expanded 


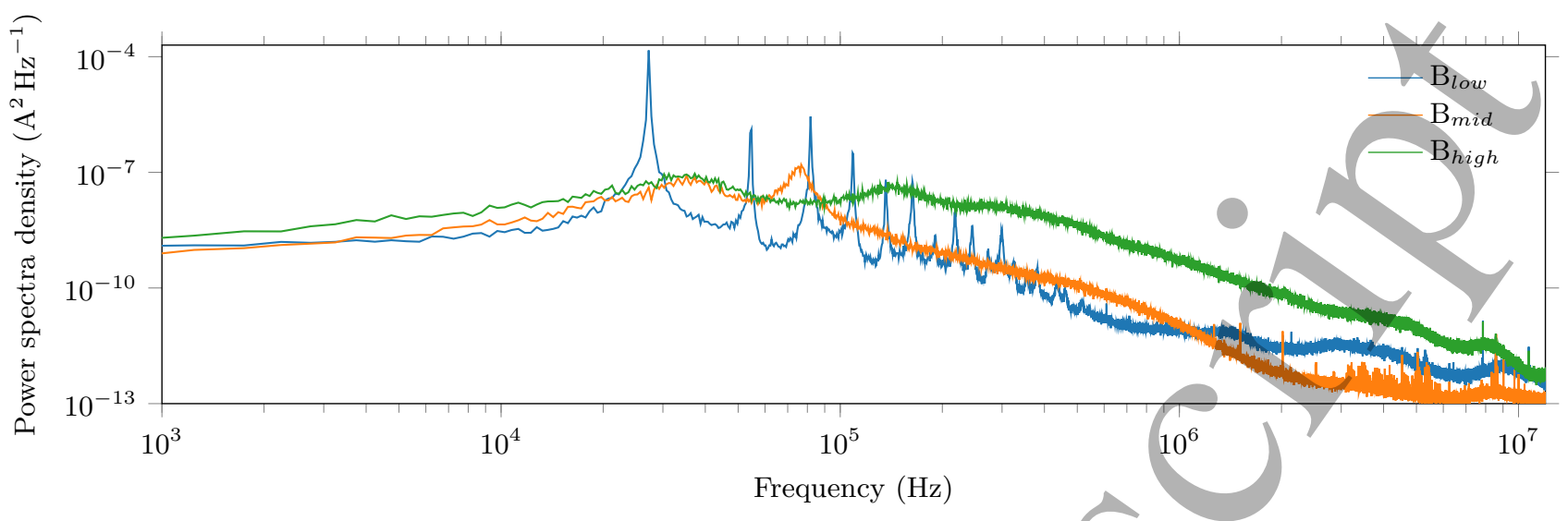

Figure 9: Power density spectra of the discharge current for the $\mathrm{B}_{l o w}, \mathrm{~B}_{\text {mid }}$ and $\mathrm{B}_{\text {high }}$ magnetic field intensities, for the conditions of Figure 8.

by a $45^{\circ}$ plume divergence angle) we obtain an estimated electron density of $10^{17} \mathrm{~m}^{-3}$ at $10 \mathrm{~mm}$ from the exit plane. The slightly lower values measured at this position (a few $10^{16} \mathrm{~m}^{-3}$ in Figure 7) may be attributed to lower ionization efficiency or higher thruster divergence than that used to estimate the density.

\subsubsection{Magnetic field configuration}

The difference in electron properties between the standard (ISCT200-GEO) and magnetically-shielded configurations (ISCT200-MS) was investigated with similar discharge conditions. To allow a direct comparison, the thrusters were operated at identical discharge power levels. The ISCT200-GEO was operated at $250 \mathrm{~V}, 1.18 \mathrm{mg} \mathrm{s}^{-1}$ in the $\mathrm{B}_{\text {low }}$ configuration, with the magnetic field directed towards the outer pole. These conditions gave a discharge power of $285 \mathrm{~W}$. The shielded ISCT200-MS was operated at $250 \mathrm{~V}, 1.05 \mathrm{mg} \mathrm{s}^{-1}$ for a discharge power of $285 \mathrm{~W}$. The corresponding magnetic field was directed towards the inner pole.

The comparisons between the two architectures are shown in Figure 10. As seen in the first row of Figure 10, higher electron densities are reached with the ISCT200-MS, up to $4 \times 10^{16} \mathrm{~m}^{-3}$. This difference with the ISCT200-GEO, operated at the same discharge conditions, can be explained by the downstream shift of the ionization and acceleration position [51] of the shielded ISCT200-MS.

Electron temperature is plotted on the second row of Figure 10. Much higher electron temperatures are found with the ISCT200-MS Hall thruster, reaching as high as $75 \mathrm{eV}$. Recent simulations also report much higher electron temperatures with a magneticallyshielded thruster than with a standard magnetic configuration, a feature associated with a downstream shift of the axial profile [66]. Nevertheless, absolute values of electron temperature from Ref. 66 are lower: only $30 \mathrm{eV}$ is reached with the standard configuration, while and $53 \mathrm{eV}$ is attained with the MS configuration. The difference between the electron temperatures from simulations and experiments under similar conditions is yet to be understood, but it is possible that the contribution of plasma instabilities - not captured in the simulations - may contribute to electron heating to some degree. The effect of instabilities such as the electron cyclotron drift instability and the modified two-stream instability in electron heating has been demonstrated in several Hall thruster simulations in recent years, including in Refs. 14, 17, 24, 67, 68.

Drift velocities for the two architectures are presented in the third row of Figure 10. In the magnetic shielding configuration, the spectral shift of the Thomson spectra at positions near the exit plane is much more significant than for the standard architecture and the measured drift velocity can be better interpreted.

For previous measurements on a planar magnetron [46], we reported sensitivity for electron drift velocity estimation as low as the velocity corresponding to the Doppler shift associated to a spectral width of one pixel (at the corresponding wavelength). This sensitivity would correspond to approximately $100 \mathrm{~km} \mathrm{~s}^{-1}$ with the 600 lines $\mathrm{mm}^{-1}$ grating and the 8-pixel wavelength binning used for this paper. Nevertheless, the Thomson scattering signal obtained from the Hall thruster plasma is more challenging to analyze because of the lower signal-to-noise ratio and distortion of the Thomson spectrum by plasma emission lines. For this reason, electron drift velocities below $500 \mathrm{~km} \mathrm{~s}^{-1}$ obtained in this campaign were not considered for data discussions. This lower limit corresponds to the drift velocity associated with the Doppler broadening of the FWHM of the instrument profile. In the figures where 


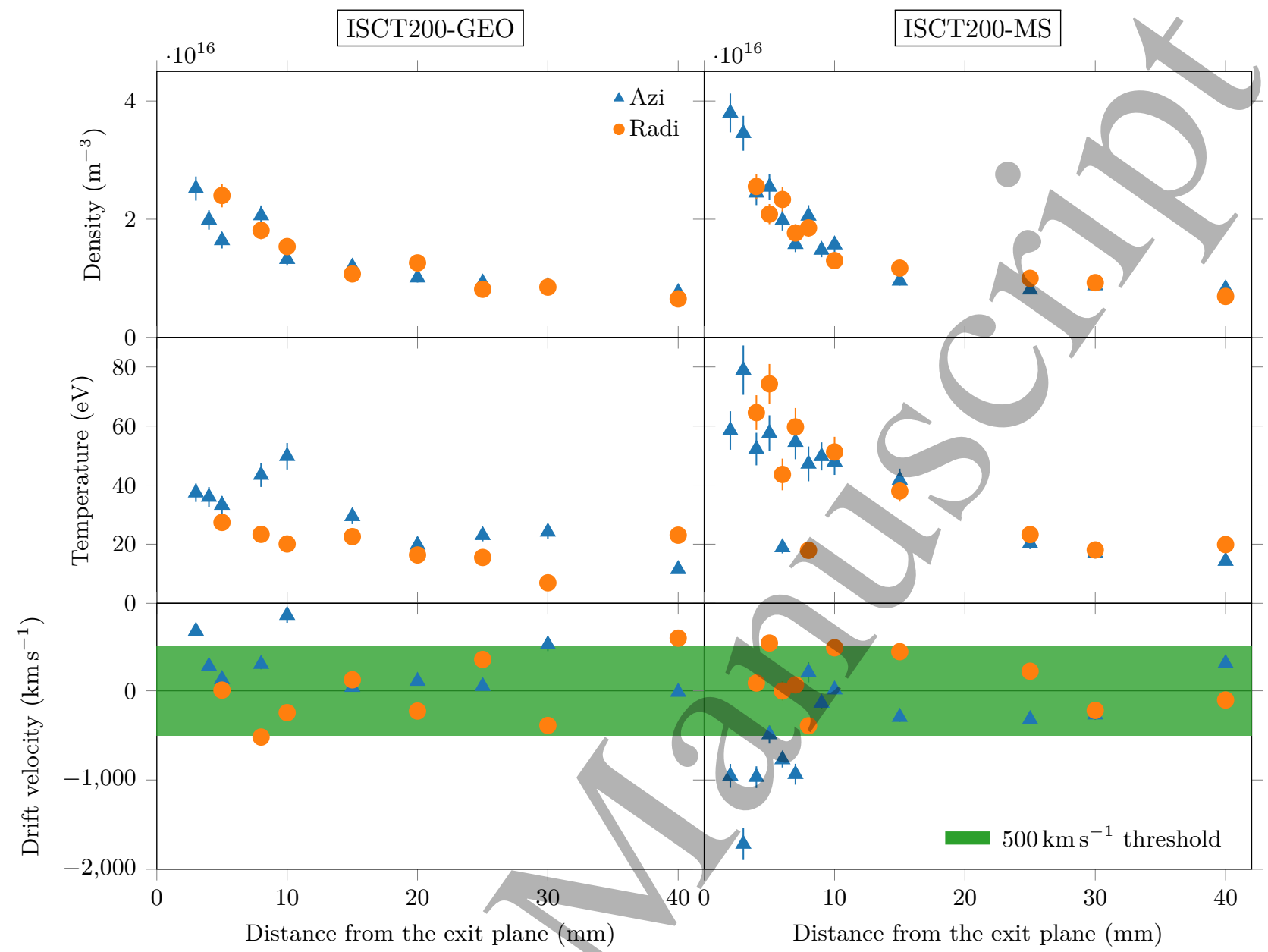

Figure 10: Comparison of electron density, temperature and and drift velocity along both azimuthal and radial directions. The discharge conditions are fixed to at $250 \mathrm{~V}$ and $1.14 \mathrm{~A}$ both magnetic field configurations: standard ISCT200-GEO (left column) and unshielded ISCT200-MS (right column)

the estimated drift velocity is shown, a green strip is drawn in order to indicate this threshold.

The electron drift velocity direction and magnitude along the azimuthal direction are expected to be easier to predict because the $\vec{E} \times \vec{B}$ drift should be one of the dominant contributions in the acceleration region. Given the magnetic and electric field orientations in the acceleration region, the azimuthal drift velocity of electrons is expected to be anti-clockwise with the ISCT200-GEO (facing the ion beam) and clockwise for the ISCT200-MS. Along the radial direction, it is more difficult to predict the drift velocity trend as other contributions, such as curvature and gradient drifts, may be on a similar order. With the ISCT200-GEO, the electron drift velocity along the azimuthal direction is systematically positive with only a few values above the threshold of $500 \mathrm{~km} \mathrm{~s}^{-1}$. As expected, these positive values correspond to electrons drifting in the clockwise direction. Along the radial direction, the drift velocity is weaker and oscillates around zero.
With the ISCT200-MS the azimuthal drift velocity is significantly negative close to the thruster exit plane. These negative values are due to the reversed magnetic field direction and are consistent with a clockwise $\vec{E} \times \vec{B}$ drift. Such significant values of electron drift velocity are observable only with the ISCT200-MS because the acceleration region, where the electric field is strong, is shifted downstream, rendering it accessible to the ITS probing beam. As with the standard configuration, electron drift velocities in the radial direction are comparatively low.

\subsubsection{Magnetic field direction}

To gain further insight into the electron drift velocity values, investigations were performed on the same ISCT200-MS thruster with the magnetic field directed towards the outer, and then inner, poles. Similar discharge conditions used for comparison with the ISCT200-GEO in Section 3.2.2 were used. With 
the magnetic field directed towards the outer pole, a discharge voltage of $250 \mathrm{~V}$, with $1.14 \mathrm{~A}$ discharge current for a xenon flow rate of $1.2 \mathrm{mg} \mathrm{s}^{-1}$, was used. With the magnetic field directed towards the inner pole, the same discharge power was used, at $250 \mathrm{~V}$ with a xenon flow rate of $1.05 \mathrm{mg} \mathrm{s}^{-1}$. This $15 \%$ increase in the required propellant flow rate suggests the influence of the magnetic field direction on the thruster performance is not negligible.

As shown in the two first rows of Figure 11 electron temperature and density profiles are only weakly affected by the magnetic field direction. In contrast, the electron drift velocity is significantly affected. Along with both the azimuthal and radial directions, the electron drift velocity switches in sign when the direction of the magnetic field is switched. When the magnetic field direction is reversed, the magnetic field gradient and curvature are expected to remain the same, with only the $\vec{E} \times \vec{B}$ contribution to the electron drift velocity expected to change.

The fact that the measured drift is of nearly the same magnitude regardless of the magnetic field direction suggests that the $\vec{E} \times \vec{B}$ drift dominates the diamagnetic and curvature drifts near the exit plane. This observation might differ at distances further downstream [69]. The maximum electron drift velocity can be used to estimate the maximum electric field in the acceleration region of the thruster. For a magnetic field of approximately $15 \mathrm{mT}$ where electron drift velocity reaches its maximum value of $1800 \mathrm{~km} \mathrm{~s}^{-1}$, the electric field would be $27 \mathrm{kV} \mathrm{m}^{-1}$. LIF measurements performed on the same thruster at lower discharge voltage $(200 \mathrm{~V})$ and $1 \mathrm{mg} \mathrm{s}^{-1}$ of xenon flow gave a slightly higher maximum value $\left(38 \mathrm{kV} \mathrm{m}^{-1}\right)$ in Ref. 70.

\subsection{Discussion on the high electron temperatures observed}

The results from these experiments show electron temperatures easily reaching $60 \mathrm{eV}$ for certain conditions, a result which does not match any typical probe measurements on large and small thrusters, where authors have previously measured temperatures in the range of few tens of $\mathrm{eV}$ in the near-field/region, for example, in Refs. 25, 28 and in Ref. 71 , where for a similar discharge voltage in a larger thruster, the electron temperature is only $30 \mathrm{eV}$ in the acceleration region.

We first consider examples of temperatures in the $60 \mathrm{eV}$ range, using spectra obtained on the ISCT200MS $2 \mathrm{~mm}$ from the exit plane with the same discharge condition as Section 3.2.3. These spectra are shown in Figure 12 and concern magnetic fields directed towards and away from the inner pole. The corresponding electron properties, deduced from Gaussian fits to these spectra, are shown in the Figure legend.
The following observations may be made:

(i) As discussed in Section 3.2.3, the presence of a strong drift shifts the center of the spectrum away from the laser frequency, and a switch in the magnetic field direction (from directed outwards to inwards) also switches the direction of this shift. This is clearly visible in Figure 12.

(ii) In addition to the spectral shift, the spectra are asymmetric. A long tail is visible along the spectral direction associated with the electron drift velocity, while the opposite side of the spectrum shows a fast decrease of signal intensity. These characteristics are consistent with nonMaxwellian EVDFs, and therefore, the presence of electrons which are not in thermal equilibrium. While a Gaussian fit may not be strictly relevant, it can still reasonably fit one side of the spectrum, and the electron temperature is estimated from such a fit. The spectra shown, though much noisier than the example provided in Figure 5 and Figure 6, are still sufficiently well-resolved to show their wide spectral range.

(iii) Lastly, we consider challenges associated with the analysis of these spectra. The high-electron temperature, low-electron density regime of the cases shown results in low-amplitude, broad Thomson spectra. These spectral features, combined with the presence of several residual emission lines, contribute to the noisiness of the data. In spite of this, the large spectral width of the cases shown is unambiguous.

What contributes to this relatively large width? We may speculate that this observation is due to oscillatory discharge behavior, averaged out during the 10-minute acquisition time for each spectrum. Although we have sought to limit these investigations to regimes in which the discharge current standard deviation is low, this does not rule out the possible influence of high-frequency plasma instabilities [17] which may generate electric field fluctuations. The accelerating potential is not truly stationary. This may create oscillations in the bulk distribution which, when averaged, would appear as unusually broad spectra, leading to apparently higher electron temperatures than would be expected from the average applied potential. To avoid this, it would be necessary to obtain a highly time-resolved measurement (ideally, a single shot measurement with shorter laser pulse duration), at present beyond reach for these low plasma densities. In addition to this effect, high-frequency instabilities have been demonstrated to contribute to true electron heating in thrusters. This dynamic heating is discussed in a number of works, including in Ref. 67, where electron temperatures reaching the $100 \mathrm{eV}$ range have been mentioned. It is worth 


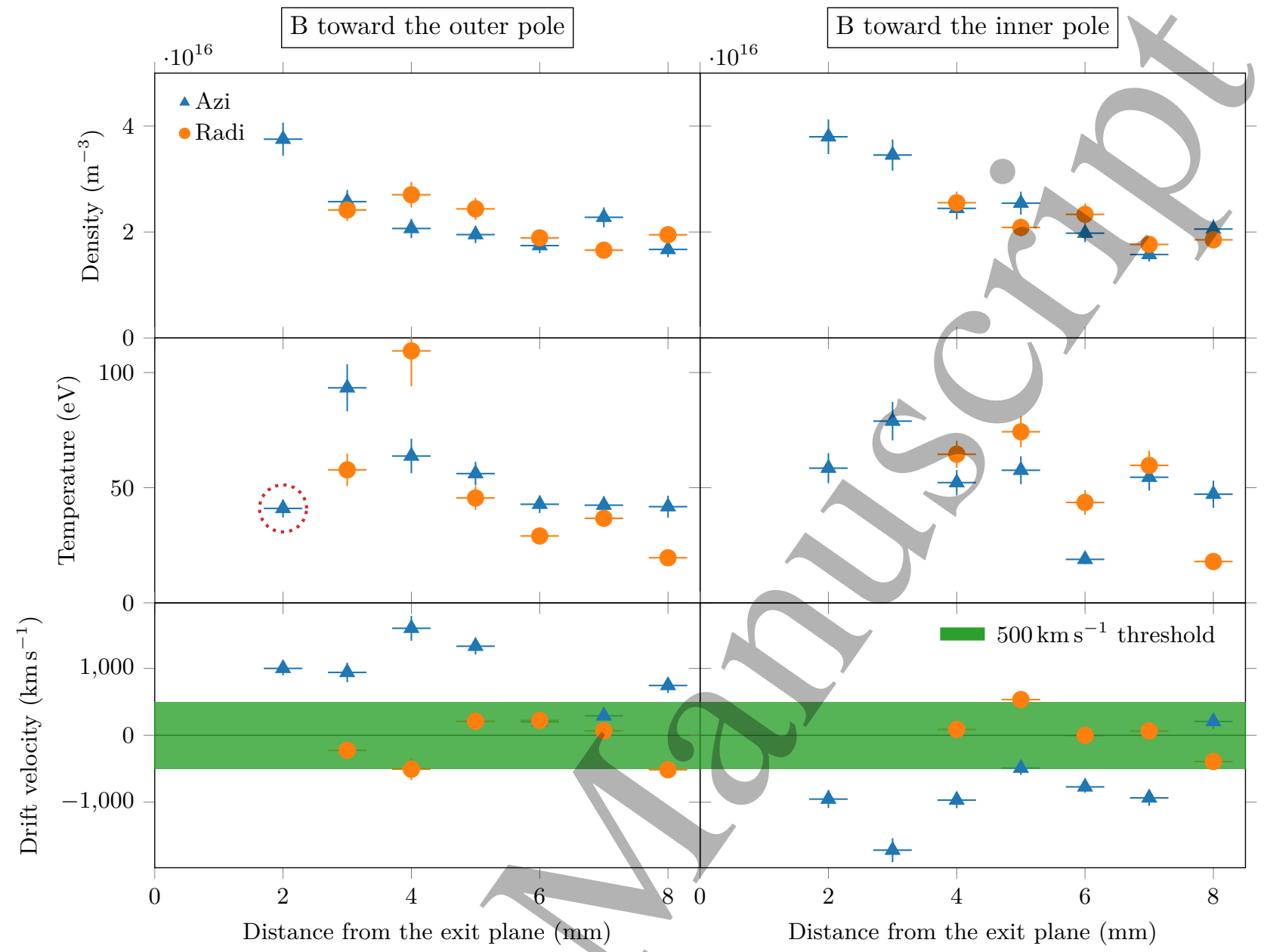

Figure 11: Comparison of electron density, temperature and drift velocity along both azimuthal (points in blue) and radial (points in orange) directions for the shielded ISCT200-MS thruster. The discharge conditions are fixed to at $250 \mathrm{~V}$ and $1.14 \mathrm{~A}$ for both magnetic field directions: towards the outer pole (left column) and towards the inner pole (right column).

noting that these simulations do not fully account for the energy dissipation mechanisms for electrons. Nevertheless, a full understanding of the contribution of plasma oscillations to the experimentally-measured spectral widths may be achievable through numerical modeling, to be examined in future work.

Further insights into electron behavior may be obtained from the calculation of the electron velocity distribution function from the Thomson spectrum profile [72]. However, this would require a higher signal-to-noise ratio, as discussed in Ref. 45, obtained for example under discharge conditions with higher electron densities.

\subsection{Influence of the discharge voltage}

Lastly, a study of the influence of the discharge voltage on the electron properties was performed, at a fixed position $2 \mathrm{~mm}$ from the exit plane. Observations were made along the azimuthal direction. The discharge voltage was varied from $112 \mathrm{~V}$ to $300 \mathrm{~V}$ at constant discharge power of $300 \mathrm{~W}$, with an adjustment of the xenon mass flow rate from $2.3 \mathrm{mg} \mathrm{s}^{-1}$ to $0.9 \mathrm{mg} \mathrm{s}^{-1}$. The investigations were performed on the ISCT200-MS with the magnetic field directed toward the external pole. At the axial position probed, electron drift velocity is expected to be dominated by the $\vec{E} \times$ $\vec{B}$ contribution, giving an anti-clockwise rotation of electrons.

As seen in Figure 13, the electron density is significantly lower at higher discharge voltages. This trend might be expected from the decrease in xenon mass flow rate imposed in order to maintain the discharge power at $300 \mathrm{~W}$ when the voltage is increased.

Provided that the accelerated ions have undergone most of the voltage drop at the position probed, their 


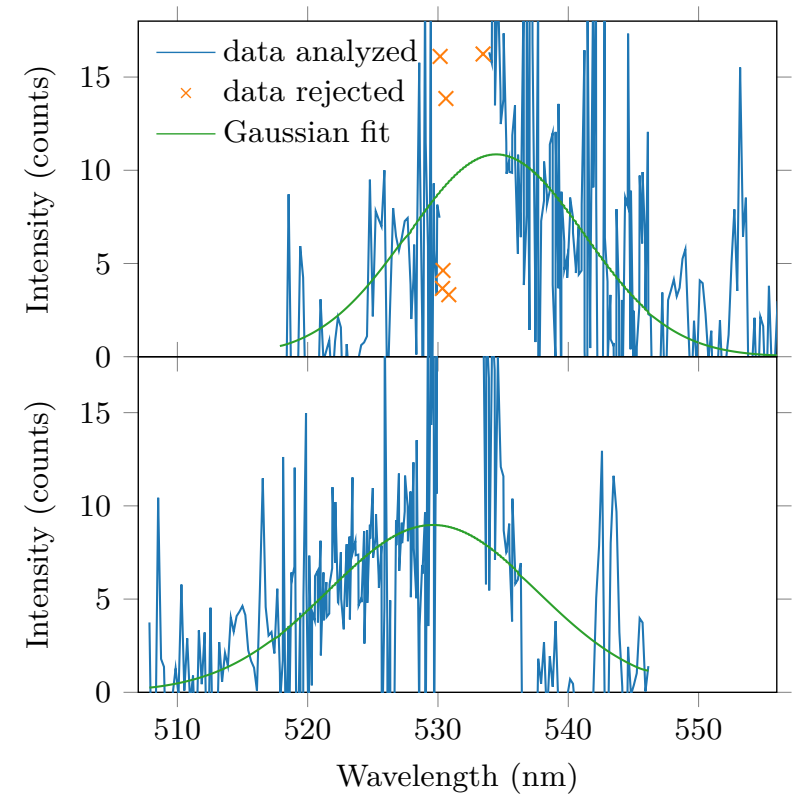

Figure 12: Thomson specta obtained along the azimuthal direction $2 \mathrm{~mm}$ from the exit plane of the ISCT200-MS thruster, for $250 \mathrm{~V}$ discharge voltage and 1.14 A discharge current (same conditions as Section 3.2.3). Top: magnetic field directed towards the outer magnetic pole; $n_{e}=(3.8 \pm 0.3) \times 10^{16} \mathrm{~m}^{-3}$, $T_{e}=(41 \pm 4) \mathrm{eV}$ and $v_{e, d r i f t}=(1000 \pm 100) \mathrm{km} \mathrm{s}^{-1}$. Bottom: magnetic field directed towards the inner magnetic pole; $n_{e}=(3.5 \pm 0.2) \times 10^{16} \mathrm{~m}^{-3}$, $T_{e}=(58 \pm 7) \mathrm{eV}$ and $v_{e, \text { drift }}=(-950 \pm 130) \mathrm{km} \mathrm{s}^{-1}$.

axial velocity can be expressed as $v_{i} \approx \sqrt{q U_{d} / m_{i}}$, where $U_{d}$ is the discharge voltage and $q$ is the elementary charge (with only singly-charged ions considered). Substituting this expression of the velocity into Equation 2, under the hypothesis of a constant ionization efficiency $\left(\eta_{\text {prop }}\right)$ and divergence angle (i.e., $A$ is constant), the product $n_{e} \sqrt{U_{d}}$ will be proportional to the xenon mass flow rate $m_{n}$.

A constant discharge power is equivalent to a fixed value of the product $I_{d} U_{d}$, and equivalent to a constant value of $m_{n} U_{d}$, since $I_{d} \propto m_{n}$. The constant discharge power can also be expressed as $n_{e} U_{d}^{3 / 2}$, using the substitution of $n_{e} \sqrt{\overline{U_{d}}}$ for the mass flow rate in $m_{n} U_{d}$. We can refer to the constant discharge power as $c$. The value of $c$ is slightly lower at $300 \mathrm{~V}$ than at $112 \mathrm{~V}$, whereas it would be expected to be constant. This observation is likely consistent with a slight axial shift in the accelerating electric field profile (meaning that the measurement, conducted at a fixed axial position, misses the peak density), or potentially, an increase in the propellant efficiency [73] as the voltage is increased. Measurement of the full axial profiles of the electron properties at several different voltages would allow for

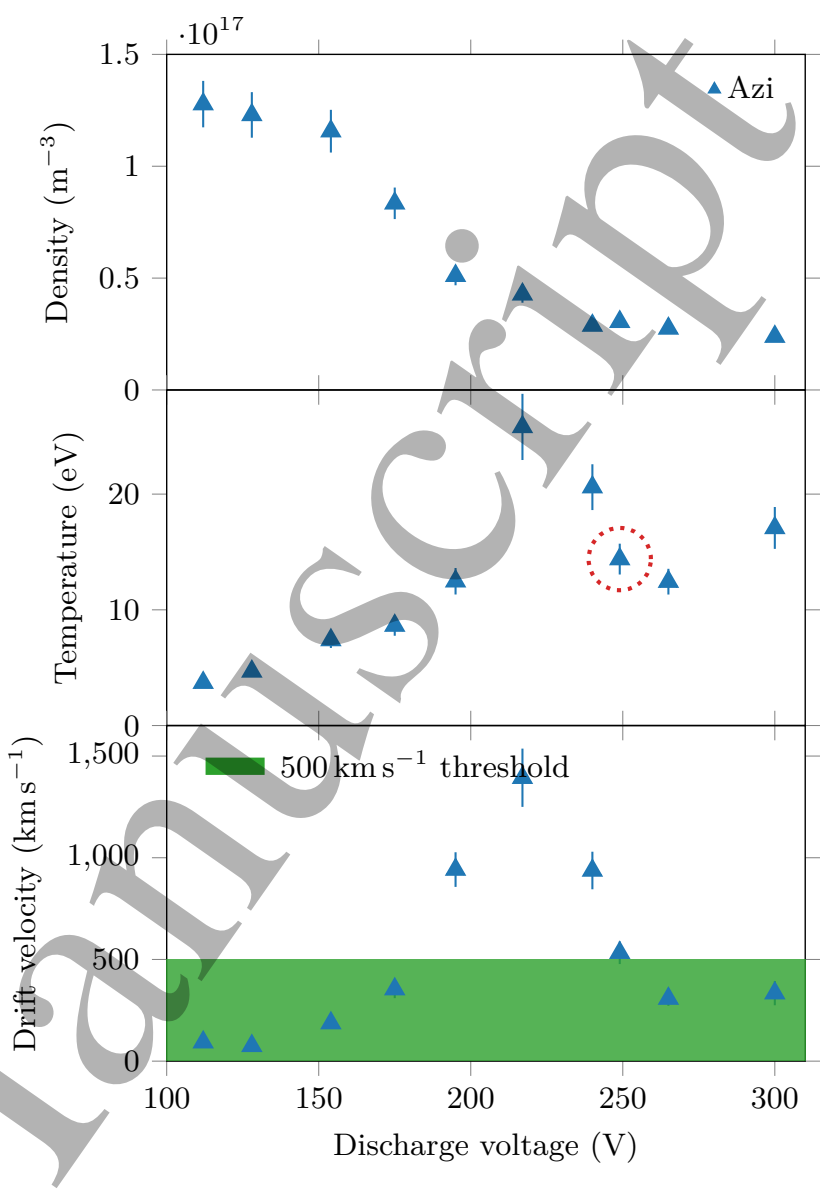

Figure 13: Electron density, temperature and drift velocity along the azimuthal direction $2 \mathrm{~mm}$ from the exit plane for the ISCT200-MS thruster. Various discharge voltages were investigated at a fixed power of $300 \mathrm{~W}$.

more detailed interpretations.

The relatively large electron densities obtained with the ISCT200-MS at low discharge voltages facilitate the analysis of the Thomson signal. Near the exit plane, quantitative deviations from the typical Gaussian form of the Thomson spectra were also observed at low voltages and will be analyzed and discussed in a forthcoming paper.

The variation in electron temperature shown in Figure 13 is non-monotonic. At low discharge voltage, electron temperature first rises linearly from $8 \mathrm{eV}$ (see Figure 6) to $13 \mathrm{eV}$ before a fast increase to $25 \mathrm{eV}$ at $217 \mathrm{~V}$, followed by a slow decrease to around $15 \mathrm{eV}$ at higher voltages.

Previous studies [74] using probes investigated the influence of channel width and discharge voltage on the maximum electron temperature. It was reported that regardless of the channel width, a linear increase of the maximum electron temperature was observed at low discharge voltages, with saturation in temperature 
observed around $60 \mathrm{eV}$ at large discharge voltages.

The trend of the electron temperature can best be interpreted by considering the effect of varying voltage on the position of the peak electric field. For the ISCT200-MS, there is a tendency for the electric field get broader and shift further outwards as the discharge voltage increases, at least for the voltage range $(200$ to $300 \mathrm{~V})$ considered in Ref. 51 . This trend contrasts with some other observations, including on a larger shielded thruster [75, 76], where the electric field instead shifts upstream as voltage increases. If the electron temperature is correlated with drift velocity, as expected [66], then the peak in the temperature may appear to be situated at $217 \mathrm{~V}$ because for this voltage, the peak electric field coincides with the observation volume position $2 \mathrm{~mm}$ from the exit plane. The subsequent decrease in the electron temperature at higher voltages would merely be due to the peak electric field moving further downstream of the observation volume position. This explanation would be valid even if the electric field instead shifts upstream as voltage increases; the key point is that a voltage change produces shifts in the electric field not necessarily captured by a fixed observation volume position. A more complete experiment would involve investigations of the electron properties at several axial positions for each voltage.

As shown in Section 3.2.3, at a position $2 \mathrm{~mm}$ from the exit plane, the electron drift velocity is dominated by the $\vec{E} \times \vec{B}$ contribution, and thus the electric field is proportional to the azimuthal drift velocity. This accounts for why the trend in electron drift velocity, shown in Figure 13 is similar to that of the electron temperature, which, as we have discussed, depends on the electric field. As with the electron temperature, the drift velocity profile is a reflection of the progressive axial shift of the peak electric field into, and then out of, the fixed observation volume.

The temporal profiles and power density spectra of the discharge current for a number of discharge voltages are shown in Figure 14 and Figure 15. The discharge current main oscillations are in the $2 \times 10^{5} \mathrm{~Hz}$ range at higher discharge voltage and may be consistent with transit time oscillations. At lower discharge voltages, oscillations in the discharge current are more concentrated in the $4 \times 10^{4} \mathrm{~Hz}$ (breathing mode) range At the lowest discharge voltage of $112 \mathrm{~V}$, current oscillations are significant with a peakto-peak amplitude as large as the mean current, with rotating spokes expected to appear [77,78]. With this discharge mode, the power spectra of the oscillations cover a broadband in the $10^{4} \mathrm{~Hz}$ range, but with welldefined oseillations, synchronization of the Thomson signal acquisition with different points in the discharge current period appears achievable, giving access to time-resolved measurements of the electron properties.

At an intermediate discharge voltage, near $217 \mathrm{~V}$, there is a minimum in the power density integrated over the entire frequency range, yet the measured electron temperature is maximum for this voltage. As discussed previously, it is not yet possible to rule out the contributions of high-frequency instabilities (not visible in the discharge current measurement) to the apparent high electron temperatures. Analysis of the discharge current frequency content can only capture oscillations in the ion (and to a smaller degree, electron) current. The frequency of the discharge current oscillations depends on the charged particle flow and does not necessarily reflect the actual frequency of instabilities involved in electron heating. Azimuthal instabilities in the $\mathrm{MHz}$ frequency range, for example, such as those identified in experiments in Refs. 79 and 34, could potentially appear in the discharge current frequency spectrum, provided (i) they produce ion or electron current fluctuations at the same frequencies as the instabilities themselves, and that (ii) these fluctuations in current are large enough to be identifiable in the frequency spectrum of the discharge current. However, given the complex way in which azimuthal instabilities contribute to electron heating and transport 14,21, the discharge current frequency content alone is not a sufficiently sensitive diagnostic for their presence and contribution to the electron dynamics.

Overall, complex modifications of the discharge properties when the discharge voltage is varied are expected. More detailed studies (experimental, possibly with coherent Thomson scattering, and numerical, possibly with particle-in-cell simulations) of the contributions of different instabilities to electron heating are required. In addition, the previous points regarding the shift of the electric field with voltage and the possible influence on the measurement can be clarified using complementary laser-induced fluorescence measurements of the electric field profile.

The discharge conditions at $249 \mathrm{~V}(300 \mathrm{~W})$ investigated during the voltage variation are similar to those at $250 \mathrm{~V}(285 \mathrm{~W})$ investigated during the axial exploration discussed in Section 3.2.2 and Section 3.2.3. However, at $249 \mathrm{~V}$ the azimuthal electron temperature at $2 \mathrm{~mm}$ (circled in Figure 13) is only about $14 \mathrm{eV}$, far below the $40 \mathrm{eV}$ azimuthal temperature at the same position at $250 \mathrm{~V}$ (circled in Figure 11).

To explain this difference, we note first that the $249 \mathrm{~V}(300 \mathrm{~W})$ discharge conditions correspond to a $5 \%$ increase of the discharge power (from $285 \mathrm{~W}$ to $300 \mathrm{~W}$ ). Given the $200 \mathrm{~W}$ nominal power of the thruster, it is not surprising that far from this power, small excursions in the discharge conditions induce changes to the averaged plasma properties such as electron 
1

2

3

4

5

6

7

8

10

11

12

13

14

15

16

17

18

19

20

21

22

23

24

25

26

27

28

29

30

31

32

33

34

35

36

37

38

39

40

41

42

43

44

45

46

47

48

49

50

51

52

53

54

55

56

57

58

59

60

ITS measurements of electron properties in a conventional and MS Hall thruster

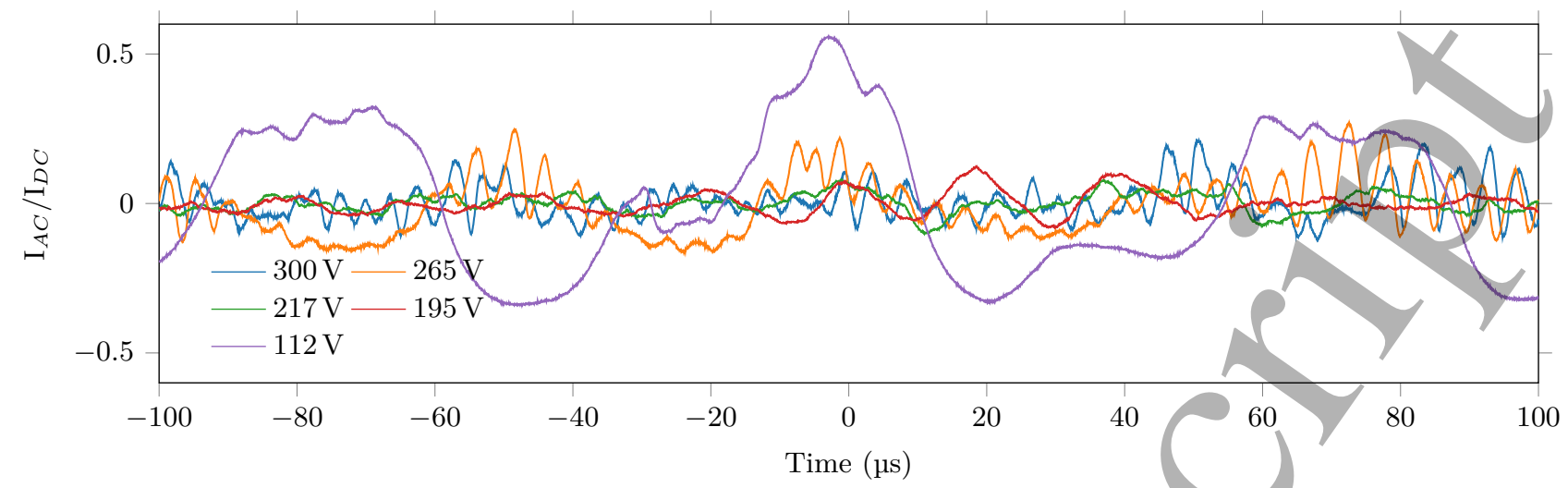

Figure 14: AC component of the discharge current for different discharge voltages for the ISCT200-MS thruster. The DC component of the current is $1.14 \mathrm{~A}$.

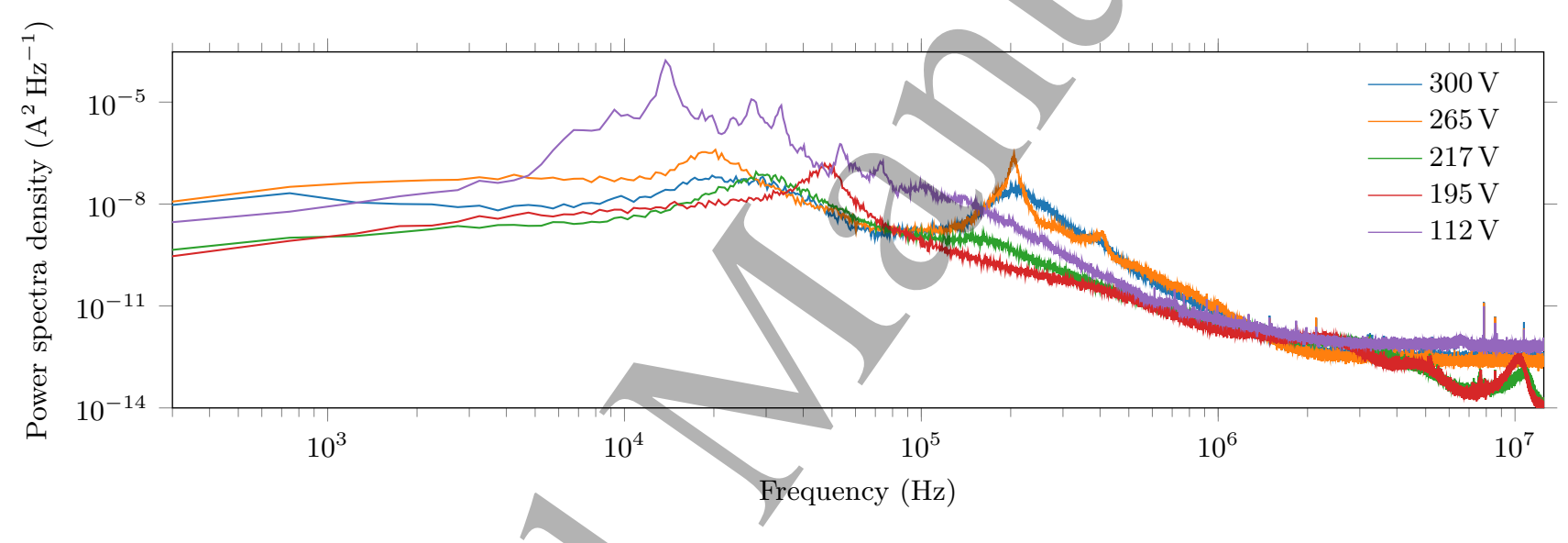

Figure 15: Power density spectra of the discharge current for different discharge voltages for the ISCT200-MS thruster, for the same conditions as Figure 14.

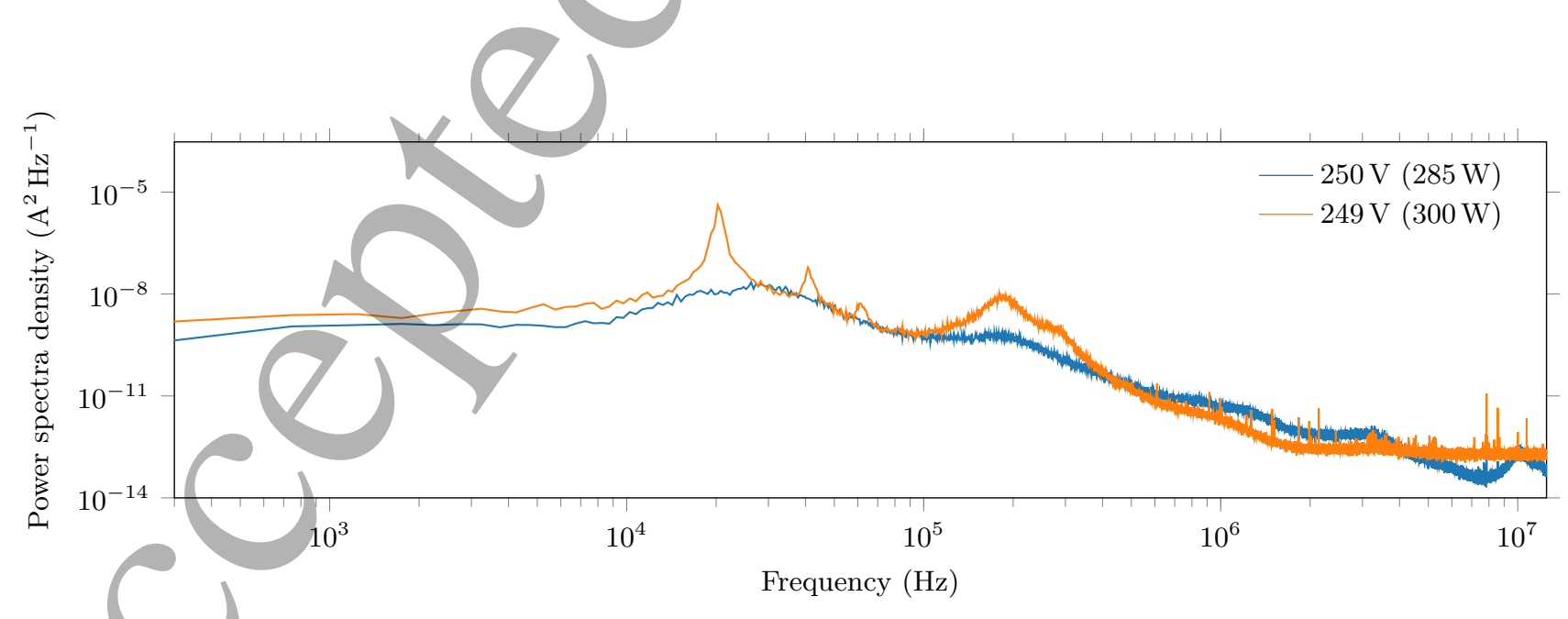

Figure 16: Power density spectra of the discharge current of the ISCT200-MS thruster associated with two similar discharge conditions. The $250 \mathrm{~V}(285 \mathrm{~W})$ conditions were used for axial explorations in Section 3.2.2 and Section 3.2.3, while the $249 \mathrm{~V}(300 \mathrm{~W})$ conditions were obtained during the discharge voltage exploration (at a fixed power) of this section. 
temperature. This point can most easily be illustrated by considering the discharge current oscillations for the $249 \mathrm{~V}(300 \mathrm{~W})$ and $250 \mathrm{~V}(285 \mathrm{~W})$ conditions.

Figure 16 shows the power density spectrum of the discharge current for the two discharge conditions. In the $10 \mathrm{kHz}$ to $100 \mathrm{kHz}$ frequency range, pronounced oscillations are present in the discharge current at $249 \mathrm{~V}(300 \mathrm{~W})$ which are absent or attenuated at $250 \mathrm{~V}(285 \mathrm{~W})$. The discharge conditions, though similar in voltage, show differing behavior which could partly account for the large difference in the measured electron temperatures for these conditions.

\section{Conclusion}

In this paper, implementations of the recentlydeveloped Thomson scattering diagnostic known as THETIS to Hall thruster investigations were presented. These studies focused on the determination of electron properties in two architectures of a $200 \mathrm{~W}$ thruster: a standard configuration and unshielded configuration. Electron properties - temperature, density, and drift velocity - were measured along both the azimuthal and radial directions.

Investigations of electron properties on the standard Hall thruster with different magnetic field intensities revealed axial profiles of electron densities in the $10^{16} \mathrm{~m}^{-3}$ range and temperatures around $25 \mathrm{eV}$. Electron properties measured on the magneticallyshielded equivalent thruster confirmed (i) the axial shift of the plasma in comparison to the standard architecture, seen in higher densities downstream of the exit plane, and (ii) large and significant non-isotropic electron drift velocities, up to $1800 \mathrm{~km} \mathrm{~s}^{-1}$ near the thruster exit plane. Reversal of the magnetic field was found to produce a reversal of the dominant $\vec{E} \times \vec{B}$ drift component at the exit plane. Discharge voltage explorations performed at a fixed axial position and discharge power revealed electron properties consistent with a shift in the electric field profile with voltage, however, complementary measurements of the axial electric field profile at different voltages are required to fully understand the influence and degree of such shifts. Large electron temperatures are apparent in many cases (exceeding what might be expected from the average applied potential), an observation which may be linked to plasma oscillations and electron heating by plasma instabilities. Combined studies (experimental and numerical) of plasma instabilities and their possible contribution to these observations will be key.

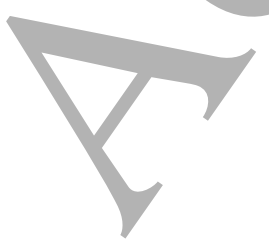

\section{Acknowledgments}

This work was supported by the French Space Agency (CNES) under the grant R \& T R-S18/PF-0005-105. The authors would like to thank C. Boniface, T. Minea, J. Fils, J. Schwindling, O. Tuske, and G. Largeau.

\section{References}

[1] Choueiri E Y 2004 Journal of Propulsion and Power 20 193-203 ISSN 0748-4658 URL http: //arc.aiaa.org/doi/10.2514/1.9245

[2] Kim V, Kozubsky K, Murashko V M and Semenkin A 2007 30th International Electric Propulsion Conference 17-20

[3] Mazouffre S 2016 Plasma Sources Science and Technology $\mathbf{2 5} 033002$ ISSN 0963-0252 URL http://stacks.iop.org/ 0963-0252/25/i=3/a=033002?key=crossref . 9c6a720db6c50120415318928e7b3f98

[4] Boeuf J p/ 2017 Journal of Applied Physics 121011101 ISSN 0021-8979 URL http://aip. scitation.org/doi/10.1063/1.4972269

[5] Goebel D M and Katz I 2008 Fundamentals of Electric Propulasion (Hoboken, NJ, USA: John Wiley \& Sons, Inc.) ISBN 9780470436448 URL http://doi.wiley.com/10.1002/ 9780470436448

[6] Charles C 2009 Journal of Physics D: Applied Physics 42 ISSN 00223727

[7] Hoskins W A, Cassady R J, Morgan O, Myers R M, Wilson F, King D Q and de Grys K 2013 The 33rd International Electric Propulsion Conference 439

[8] Choueiri E Y 2001 Physics of Plasmas 8 1411-1426 ISSN 1070664X

[9] Lopez Ortega A and Mikellides I G 2016 Physics of Plasmas 23 ISSN 10897674

[10] Bugrova A 1987 Sov. Phys. Tech. Phys. 32

[11] Giono G, Gudmundsson J T, Ivchenko N, Mazouffre S, Dannenmayer K, Loubère D, Popelier L, Merino M and Olentšenko G 2018 Plasma Sources Science and Technology 27015006 ISSN 13616595 URL http://stacks.iop.org/ 0963-0252/27/i=1/a=015006?key=crossref . 3cc1b9821d68b707749e109ec7a9f5b5

[12] Barral S, Makowski K, Peradzyński Z, Gascon N and Dudeck M 2003 Physics of Plasmas 10 4137-4152 ISSN 1070664X

[13] Sydorenko D, Smolyakov A, Kaganovich I and Raitses Y 2006 Physics of Plasmas 13014501 ISSN 1070-664X URL http://aip.scitation. org/doi/10.1063/1.2158698 
[14] Héron A and Adam J C 2013 Physics of Plasmas 20082313 ISSN 1070-664X

[15] Tsikata S, Héron A and Honoré C 2017 Physics of Plasmas 24053519 ISSN 1070-664X URL http: //aip.scitation.org/doi/10.1063/1.4984255

[16] Hirakawa M and Arakawat Y 1996 Numerical simulation of plasma particle behavior in a hall thruster 32nd Joint Propulsion Conference and Exhibit July

[17] Adam J C, Héron A and Laval G 2004 Physics of Plasmas 11 295-305 ISSN 1070664X

[18] Hagelaar G J M, Bareilles J, Garrigues L and Boeuf J P 2004 Contributions to Plasma Physics 44 529-535 ISSN 08631042

[19] Hofer R R, Katz I, Mikellides I G and GameroCastaño M 2006 Collection of Technical Papers AIAA/ASME/SAE/ASEE 42nd Joint Propulsion Conference 5 3354-3370

[20] Liu H, Wu B, Yu D, Cao Y and Duan P 2010 Journal of Physics D: Applied Physics 43 ISSN 00223727

[21] Janhunen S, Smolyakov A, Chapurin O, Sydorenko D, Kaganovich I and Raitses Y 2018 Physics of Plasmas 25011608 ISSN 1070664X URL http://aip.scitation.org/doi/ $10.1063 / 1.5001206$

[22] Croes V, Lafleur T, Bonaventura Z, Bourdon A and Chabert P 2017 Plasma Sources Science and Technology 26 ISSN 13616595

[23] Hara K 2019 Plasma Sources Science and Technology $\mathbf{2 8} 044001$ ISSN 13616595 URL http://stacks.iop.org/ $0963-0252 / 28 / i=4 / a=044001$ ?key=crossref . 243ebce79772c1aba0ecfdeb581a7a99

[24] Taccogna F and Garrigues L 2019 Reviews of Modern Plasma Physics 3 12 ISSN 2367-3192 URL http://link.springer.com/10.1007/ s41614-019-0033-1

[25] Raitses Y, Staack D, Keidar M and Fisch N J 2005 Physics of Plasmas 12057104 ISSN 1070664X URL http://aip.scitation.org/doi/10. 1063/1.1891747

[26] Shastry R, Gallimore A and Hofer R 2009 Near-Wall Plasma Properties and EEDF Measurements of a $6-\mathrm{kW}$ Hall Thruster 45th AIAA/ASME/SAE/ASEE Joint Propulsion Conference 8 Exhibit August (Reston, Virginia: American Institute of Aeronautics and Astronautics) pp 1-15 ISBN 978-1-60086-972-3 URL http://arc.aiaa.org/doi/abs/10.2514/ $6.2009-5356$
[27] Dannenmayer K, Kudrna P, Tichý M and Mazouffre S 2013 Contributions to Plasma Physics 53 63-68 ISSN 08631042

[28] Tichý M, Pétin A, Kudrna P, Horký M and Mazouffre S 2018 Physics of Plasmas 25061205 ISSN 1070-664X URL http://aip.scitation. org/doi/10.1063/1.5017578

[29] Chiu Y H, Austin B L, Williams S, Dressler R A and Karabadzhak G F 2006 Journal of Applied Physics 99113304 ISSN 0021-8979 URL http: //aip.scitation.org/doi/10.1063/1.2195018

[30] Karabadzhak G F, Chiu Y H and Dressler R A 2006 Journal of Applied Physics 99 ISSN 00218979

[31] Sommerville J and King L 2006 An Optical Diagnostic for Xenon Hall Thrusters Including Metastable Contributions 42nd AIAA/ASME/SAE/ASEE Joint Propulsion Conference \& Exhibit July (Reston, Virginia: American Institute of Aeronautics and Astronautics) pp 1-9 ISBN 978-1-62410-038-3 URL http://arc .aiaa.org/doi/abs/10.2514/6. $2006-4823$

[32] Spektor R and Beiting E J 2007 IEPC-2007 1-9

[33] Grimaud L, Pétin A, Vaudolon J and Mazouffre S 2016 Review of Scientific Instruments 87043506 ISSN 0034-6748 URL http://dx.doi.org/10. 1063/1. 4945563

[34] Tsikata S 2009 Small-scale electron density fluctuations in the Hall thruster, investigated by collective light scattering Ph.D. thesis Ecole Polytechnique URL https://pastel. archives-ouvertes.fr/tel-00484027

[35] Irisawa J and John P K 1973 Review of Scientific Instruments 44 1021-1023 ISSN 00346748

[36] Bowden M D, Goto Y, Yanaga H, Howarth P J, Uchino K and Muraoka K 1999 Plasma Sources Science and Technology 8 203-209 ISSN 09630252

[37] Kono A and Funahashi H 2002 Journal of Applied Physics 92 1757-1763 ISSN 0021-8979 URL http: //aip.scitation.org/doi/10.1063/1.1493659

[38] van de Sande M J and van der Mullen J J A M 2002 Journal of Physics D: Applied Physics 35 314 ISSN 00223727 URL http://iopscience. iop.org/0022-3727/35/12/314\{\%\}5Cnhttp: //iopscience.iop.org/0022-3727/35/ 12/314/pdf/0022-3727\{_\}35\{_\}12\{_\}314. pdfhttp://stacks.iop.org/0022-3727/ $35 / i=12 / a=314$ ? key=crossref . 9624278f13ccfdd8fb598b7da1b70ad5

[39] Aramaki M, Kobayashi J, Kono A, Stamate E and Sugai H 2006 Thin Solid Films 506-507 679-682 ISSN 00406090 
[40] Yamamoto N, Tomita K, Sugita K, Kurita T, Nakashima H and Uchino K 2012 Review of Scientific Instruments $\mathbf{8 3} 073106$ ISSN 00346748 URL http://aip.scitation.org/doi/10. 1063/1.4737144

[41] Carbone E A D, Hübner S, Palomares J M and van der Mullen J J A M 2012 Journal of Physics D: Applied Physics 45345203 ISSN 0022-3727 URL http://stacks.iop.org/ $0022-3727 / 45 / i=34 / a=345203$ ?key=crossref . 27 f26d940dca $8 f b d c 7484$ f9103113f8e

[42] Crintea D L, Luggenhölscher D, Kadetov V A, Isenberg C and Czarnetzki U 2008 Journal of Physics D: Applied Physics 41082003 ISSN 0022-3727 URL http://stacks.iop.org/ $0022-3727 / 41 / i=8 / a=082003$ ?key=crossref . a36d1bba259786b4491c80fdd5af45aa

[43] Washeleski R L 2012 Laser Thomson scattering measurements of electron temperature and density in a Hall-effect plasma Ph.D. thesis Michigan Technological University URL https: //digitalcommons.mtu.edu/etds/422/

[44] Washeleski R L, Meyer E J and King L B 2013 Review of Scientific Instruments 84105101 ISSN 0034-6748 URL http://aip.scitation. org/doi/10.1063/1.4821980

[45] Vincent B, Tsikata S, Mazouffre S, Minea $\mathrm{T}$ and Fils J 2018 Plasma Sources Science and Technology $\mathbf{2 7} 055002$ ISSN 1361-6595 URL http://stacks.iop.org/ 0963-0252/27/i=5/a=055002?key=crossref . 024eb31b4d726409e335df21c76aec11

[46] Tsikata S, Vincent B, Minea T, Revel A and Ballage C 2019 Plasma Sources Science and Technology $\mathbf{2 8} \quad 03 \mathrm{LT} 02$ ISSN 1361-6595 URL http://stacks.iop.org/ 0963 $-0252 / 28 / i=3 / a=03 L T 02 ? k e y=$ crossref . 56ae02bd7c1937aabe7307d3a4f46aeb

[47] Dankanich J W, Walker M, Swiatek M W and Yim J T 2017 Journal of Propulsion and Power 33 668-680 ISSN 07484658

[48] Walker M L R 2005 Effects of Facility Backpressure on the Performance and Plume of a Hall Thruster Ph.D. thesis University of Michigan URL http://adsabs.harvard.edu/ abs/2005PhDT. . . . . 46W

[49] Lejeune A, Dannenmayer K, Bourgeois G, Mazouffre S, Guyot M and Denise S 2011 Impact of the channel width on Hall thruster discharge properties and performances IEPC-2011 pp 1-15

[50] Mazouffre S, Bourgeois G, Dannenmayer K and Lejeune A 2012 Journal of Physics D: Applied Physics $45 \quad 185203$ ISSN
0022-3727 URL http://stacks.iop.org/ $0022-3727 / 45 / i=18 / a=185203$ ?key=crossref . d29436c21e2c63e84f66965547aee922

[51] Grimaud L and Mazouffre S 2017 Plasma Sources Science and Technology 26055020 ISSN 1361-6595 URL http://dx,doi.org/10.1088/ 1361-6595/aa660d

[52] Grimaud L and Mazouffre S 2018 Vacuum 155 514-523 ISSN 0042207X URL https://linkinghub.elsevier.com/retrieve/ pii/S0042207X18306821

[53] Mikellides I, Katz I, Hofer R, Goebel D, de Grys K and Mathers A 2010 Magnetic Shielding of the Acceleration Channel Walls in a Long-Life Hall Thruster 46th AIAA/ASME/SAE/ASEE Joint Propulsion Conference \& Exhibit (Reston, Virginia: American Institute of Aeronautics and Astronautics) pp 1-25 ISBN 978-1-60086-958-7 URL http://arc.aiaa.org/doi/abs/10.2514/ 6.2010-6942

[54] Conversano R W, Goebel D M, Hofer R R, Matlock $\mathrm{T} \mathrm{S}$ and Wirz R E 2015 IEEE Transactions on Plasma Science 43 103-117 ISSN 0093-3813 URL http://ieeexplore.ieee.org/ document/6823735/

[55] de Grys K, Mathers A, Welander B and Khayms N 2010 Demonstration of 10,400 Hours of Operation on $4.5 \mathrm{~kW}$ Qualification Model Hall Thruster 46th AIAA/ASME/SAE/ASEE Joint Propulsion Conference and Exhibit July (Reston, Virginia: American Institute of Aeronautics and Astronautics) ISBN 978-1-60086-958-7 URL http://arc. aiaa.org/doi/abs/10.2514/6.2010-6698

[56] Ernst W E, Softley T P and Zare R N 1988 Physical Review A 37 4172-4183 ISSN 0556-2791 URL https : //link . aps .org/doi/10. 1103/PhysRevA. 37.4172

[57] Jiang T, Bowden M D, Wagenaars E, Stoffels E and Kroesen G M 2006 New Journal of Physics 8 ISSN 13672630

[58] Xu K G and Walker M L 2014 Journal of Propulsion and Power 30 506-513 ISSN 07484658

[59] Kawashima R, Bak J, Komurasaki K, Koizumi $\mathrm{H}$ and Hara K 2017 Effects of Azimuthal Nonuniformity on the Hall Thruster Discharge IEPC2017 pp 1-8

[60] Jarrige J, Packan D, Duchemin O and Balika L 2015 Gas in a Hall Effect Thruster using Electron Beam IEPC-2015-12 / ISTS-2015-b-12 pp 1-11

[61] Boeuf J P and Garrigues L 2018 Physics of Plasmas 25061204 ISSN 1070-664X URL http: //aip.scitation.org/doi/10.1063/1.5017033 
[62] Forslund D W, Morse R L and Nielson C W 1970 Physical Review Letters 25 1266-1270 ISSN 0031-9007 URL https://link . aps . org/doi/10. 1103/PhysRevLett. 25.1266

[63] Tavant A, Croes V, Lucken R, Lafleur T, Bourdon A and Chabert P 2018 Plasma Sources Science and Technology $\mathbf{2 7} 124001$ ISSN 1361-6595 URL http://stacks.iop.org/ 0963 $-0252 / 27 / i=12 / a=124001$ ?key=crossref . d7b2e36d56be13d9be494258477680ce

[64] Grimaud L 2018 Magnetic shielding topology applied to low power Hall thrusters Ph.D. thesis Université d'Orléans

[65] Bourgeois G 2012 Influence de la topologie magnétique, de la cathode et de la section du canal sur l'accélération des ions dans un propulseur à effet Hall Ph.D. thesis Université d'Orléans

[66] Garrigues L, Santhosh S, Grimaud L and Mazouffre S 2019 Plasma Sources Science and Technology 28034003 ISSN 1361-6595 URL https://doi.org/10.1088/1361-6595/ab080d

[67] Janhunen S, Smolyakov A, Sydorenko D, Jimenez M, Kaganovich I and Raitses Y 2018 Physics of Plasmas 25082308 ISSN 1070664X (Preprint arXiv:1804.05450v2) URL http://dx.doi.org/10.1063/1.5033896

[68] Lafleur T, Baalrud S D and Chabert P 2016 Physics of Plasmas 23 ISSN 10897674 URL http: //dx.doi.org/10.1063/1.4948495

[69] Chapurin O and Smolyakov A 2016 Journal of Applied Physics 119 243306 ISSN 00218979 URL http://aip.scitation.org/doi/10. 1063/1. 4954994

[70] Grimaud L and Mazouffre S 2017 Journal of Applied Physics 122033305 ISSN 00218979 URL http://aip.scitation.org/doi/10. 1063/1. 4995285

[71] Staack D, Raitses Y and Fisch N J 2004 Applied Physics Letters 84 3028-3030 ISSN 00036951 URL http://aip.scitation.org/doi/10. 1063/1.1710732

[72] Huang M, Warner K, Lehn S and Hieftje G M 2000 Spectrochimica Acta Part B: Atomic Spectroscopy 55 1397-1410 ISSN 05848547 URL http://linkinghub.elsevier.com/retrieve/ pii/S0584854700002445

[73] Grimaud L, Vaudolon J, Mazouffre S and Boniface C 2016 Design and characterization of a 200W Hall thruster in "magnetic shielding" configuration 52nd AIAA/SAE/ASEE Joint Propulsion Conference (Reston, Virginia: American Institute of Aeronautics and Astronautics) pp 1-17
ISBN 978-1-62410-406-0 URL http://arc .aiaa. org/doi/10.2514/6.2016-4832

[74] Raitses Y, Smirnov A, Staack D, Keidar M and Fisch N 2005 Characterization of plasma in a Hall thruster operated at high discharge voltage 41st AIAA/ASME/SAE/ASEE Joint Propulsion Conference \&S Exhibit July (Reston, Virginia: American Institute of Aeronautics and Astronautics) pp 1-6 ISBN 978-1-62410-063-5 URL http://arc.aiaa.org/doi/abs/10.2514/ 6.2005-4404

[75] Hargus W A and Cappelli M A 2002 Journal of Propulsion and Power 18 159-168 ISSN 07484658 URL http://arc.aiaa.org/doi/10.2514/ 2.5912

[76] Chaplin V H, Jorns B A, Lopez Ortega A, Mikellides I G, Conversano R W, Lobbia R B and Hofer R R 2018 Journal of Applied Physics 124183302 ISSN 0021-8979 URL http://aip. scitation.org/doi/10.1063/1.5040388

[77] Mazouffre S, Grimaud L, Tsikata S, Matyash K and Schneider R 2019 Plasma Sources Science and Technology ISSN 0963-0252 URL http://iopscience.iop.org/article/10. 1088/1361-6595/ab07fc

[78] Matyash K, Schneider R, Mazouffre S, Tsikata S and Grimaud L 2019 Plasma Sources Science and Technology 28044002 ISSN 1361-6595 URL http://iopscience.iop.org/article/10. 1088/1361-6595/ab1236

[79] Lazurenko A, Albaréde L and Bouchoule A 2006 Physics of Plasmas 13 ISSN 1070664X 